\title{
The Cyclicality of the Opportunity Cost of Employment
}

\section{Gabriel Chodorow-Reich}

Harvard University and National Bureau of Economic Research

\section{Loukas Karabarbounis}

University of Minnesota and National Bureau of Economic Research

\begin{abstract}
The flow opportunity cost of moving from unemployment to employment consists of forgone public benefits and the forgone consumption value of nonworking time. We construct a time series of the opportunity cost of employment using detailed microdata and administrative or national accounts data to estimate benefits levels, eligibility, takeup, consumption by labor force status, hours, taxes, and preference parameters. The opportunity cost is procyclical and volatile over the business cycle. The estimated cyclicality implies far less unemployment volatility in leading models of the labor market than that observed in the data, irrespective of the level of the opportunity cost.
\end{abstract}

\section{Introduction}

Understanding the causes of labor market fluctuations ranks among the most important and difficult issues in economics. In recent decades,

We are especially grateful to Bob Hall for many insightful discussions and for his generous comments at various stages of this project. This paper also benefited from comments and conversations with Mark Bils, Steve Davis, Dan Feenberg, Peter Ganong, Erik Hurst, Greg Kaplan, Larry Katz, Pat Kehoe, Guido Lorenzoni, Iourii Manovskii, Kurt Mitman, Giuseppe Moscarini, Casey Mulligan, Nicolas Petrosky-Nadeau, Richard Rogerson, Rob Shimer, Harald Uhlig, Gianluca Violante, anonymous referees, and numerous seminar participants. Much of this paper was written while Gabriel Chodorow-Reich was visiting the Julis-Rabinowitz Center at Princeton University. Loukas Karabarbounis thanks Chicago

Electronically published October 31, 2016

[ Journal of Political Economy, 2016, vol. 124, no. 6]

(c) 2016 by The University of Chicago. All rights reserved. 0022-3808/2016/12406-0006\$10.00 
economists have turned attention to models of equilibrium unemployment. These models feature optimization decisions by workers and firms along with frictions that prevent all workers from supplying their desired amount of labor.

The flow value of the opportunity cost of employment, which we denote by $z$, plays a crucial role in many such models. The importance of this variable has generated debate about its level, but the literature has almost uniformly adopted the assumption that the opportunity cost is constant over the business cycle. Fluctuations in the opportunity cost correspond loosely to shifts in desired labor supply and therefore can affect the volatility of unemployment and wages. While this insight goes back at least as far as Pissarides (1985), to date the cyclical properties of the opportunity cost in the data remain unknown.

The main contribution of this paper is to develop and implement an empirical framework to measure $z$ in the data. ${ }^{1}$ We find that, irrespective of its level, $z$ is procyclical and volatile over the business cycle. The cyclicality of $z$ poses a significant challenge to models that rely on a constant $z$ to solve the unemployment volatility puzzle highlighted by Shimer (2005). The reason is that a procyclical $z$ undoes the endogenous wage rigidity generated by these models.

We begin in Section II by deriving an expression for the opportunity cost $z$. We start our analysis within a framework that borrows elements from the search and matching model developed in Mortensen and Pissarides (1994). We show, however, that the same measure of $z$ also arises naturally in many other environments. For example, the same expression for $z$ plays an important role in models that allow for ex ante heterogeneity across workers, models that use alternative wage bargaining protocols, and models with directed instead of random search. In this wide class of models, fluctuations in equilibrium unemployment depend on the behavior of $z$ relative to the behavior of the after-tax marginal product of employment (which we denote by $p^{\tau}$ ).

We write the opportunity cost of employment as the sum of two terms, $z=b+\xi$. The first term, which we denote by $b$, is the value of public benefits that unemployed forgo upon employment. Our expression for $b$ departs from the literature in three significant ways. First, we argue that $b$ should depend on effective rather than statutory benefit rates. Second, we consider both unemployment insurance (UI) benefits, which are di-

Booth for summer financial support. The appendix and data set that accompany this paper are available on the Journal's website. The views expressed herein are those of the authors and not necessarily those of the Federal Reserve Bank of Minneapolis or the Federal Reserve System.

${ }^{1}$ Our approach complements recent research that uses surveys to ask respondents directly about their reservation wage (Hall and Mueller 2013; Krueger and Mueller 2013). Relative to survey estimates, our approach allows us to construct a long time series for $z$, which is crucial for studying cyclical patterns. 
rectly related to unemployment status, and non-UI benefits such as supplemental nutritional assistance (SNAP), welfare assistance (AFDC/TANF), and health care (Medicaid). The latter belong in the opportunity cost to the extent that receipt of these benefits changes with unemployment status. Third, we take into account UI benefits expiration, incorporate taxes, and model and measure the utility costs associated with taking up UI benefits (for instance, job search costs and other filing and time costs). These utility costs allow the model to match the fact that roughly one-third of eligible unemployed do not actually take up UI benefits.

In Section III we measure $b$ over the period 1961(1)-2012(4). For the measurement of $b$ we require time series of UI and non-UI benefits per unemployed. Combining household and individual-level data from the Current Population Survey (CPS) and the Survey of Income and Program Participation (SIPP) with program administrative data, we estimate the value of UI, SNAP, AFDC/TANF, and Medicaid benefits that belong in $b$. We further incorporate into our measurement of $b$ the time series of UI eligibility, take-up rates, and number of recipients. Finally, we use Internal Revenue Service Public Use Files to estimate tax rates on UI benefits.

Our estimated $b$ is countercyclical, rising around every recession since 1961. However, because we incorporate effective rather than statutory rates and because we account for costs associated with UI take-up and for the expiration of UI benefits, the level of $b$ is much smaller than what the literature has traditionally calibrated. We find that $b$ is only 6 percent of the sample average of the after-tax marginal product of employment $p^{\tau}$.

The second term of the opportunity cost of employment $z=b+\xi$, which we denote by $\xi$, is the forgone value of nonworking time expressed in units of consumption. With concave preferences over consumption and a positive value of nonworking time, this component resembles the marginal rate of substitution between nonworking time and consumption in the real business cycle (RBC) model, with the difference being that the value of nonworking time is calculated along the extensive margin. In the RBC model, an intraperiod first-order condition equates the marginal rate of substitution between nonworking time and consumption to the after-tax marginal product of labor. While the search and matching literature has appealed to this equality to motivate setting the level of $z$ close to that of the marginal product, the same logic suggests that the $\xi \mathrm{com}-$ ponent of $z$ would move cyclically with the marginal product just as in the RBC model.

We measure the $\xi$ component of the opportunity cost in Section IV. For the measurement of $\xi$ we require estimates of preference parameters and time series of consumption expenditures by labor force status, hours per worker, and labor income and consumption taxes. The consumptions of the employed and unemployed do not have direct counterparts in existing data sources. We generate time series of consumptions using esti- 
mates of relative consumption by labor force status from the Consumer Expenditure Survey (CE) and the Panel Study of Income Dynamics (PSID), population shares by labor force status, and National Income and Product Accounts (NIPA) consumption of nondurables and services per capita. We measure hours per worker from the CPS. Finally, we use IRS Public Use Files to estimate tax rates on labor income and NIPA data to measure effective taxes on consumption.

The measurement of $\xi$ also depends on preference parameters, which we calibrate for various common utility functions. We discipline preference parameters by requiring that the steady state of the model be consistent with empirical estimates of hours per worker and the consumption decline upon unemployment. We present specifications that result in levels of $z$ ranging from 0.47 to 0.96 relative to an after-tax marginal product of employment equal to $p^{\tau}=1$. We show how the level of $z$ across these specifications depends on estimates of the total endowment of utilityenhancing time, the curvature of the utility function, and fixed time or utility costs associated with working.

We find that the $\xi$ component of the opportunity cost is highly procyclical, irrespective of its level. This procyclicality reflects the procyclical movements in consumption and hours per worker. Intuitively, $\xi$ falls in recessions because the household values more the contribution of the employed (through higher wage income) relative to that of the unemployed (through higher nonworking time) in states of the world in which consumption is low and nonworking time is high.

Combining the opportunity cost associated with benefits $b$ with the opportunity cost associated with the value of nonworking time $\xi$, Section $\mathrm{V}$ shows that our time series of $z=b+\xi$ is procyclical and volatile. The procyclicality of $z$ reflects the outcome of two opposing forces. In the absence of $\xi$, fluctuations in $b$ would imply a countercyclical $z$. However, because the level of $b$ is much smaller than the level of $\xi$, the procyclical $\xi$ component accounts for the majority of the fluctuations in $z$.

The elasticity of the cyclical component of $z$ with respect to the cyclical component of the marginal product of employment $p$ is an informative summary statistic when assessing the performance of a large class of models. Across specifications, this elasticity exceeds 0.8 and is typically close to one. Importantly, $z$ comoves roughly proportionally with $p$ over the business cycle irrespective of whether the level of $z$ is high or low. The positive and large elasticity appears robust to a number of alternative modeling choices and data moments, including replacing the hours per worker series with hours per worker for hourly workers, salaried workers, or an hours series adjusted for compositional changes over the business cycle, changing the estimated decline in consumption upon unemployment, using an alternative model of UI take-up, and introducing fixed time and utility costs associated with working. 
In Section VI we extend our framework to allow for heterogeneity across workers with different educational attainments. While this exercise reveals interesting variation in the level and composition of $z$ across skill groups, each of the skill-specific $z$ 's is procyclical. The same economic forces that cause fluctuations in the aggregate $z$ over the business cycle also influence the skill-specific z's. Quantitatively, the lowest skill groups exhibit a more elastic $z$ over the business cycle than the highest skill groups.

Section VII turns to the implications of our estimated $z$ for models of unemployment fluctuations. We start with models in the MortensenPissarides class. As emphasized in influential work by Shimer (2005), the standard Mortensen-Pissarides model with wages set according to Nash bargaining fails to account quantitatively for the observed volatility of unemployment. Some of the leading solutions to this unemployment volatility puzzle rely on a constant $z$ to reduce the procyclicality of wages. The cyclicality of $z$ dampens unemployment fluctuations in these models. The logic of this result is quite general and does not depend on the set of primitive shocks driving the business cycle. Relative to the constant $z$ case, a procyclical $z$ increases the surplus from accepting a job at a given wage during a recession, which puts downward pressure on equilibrium wages and ameliorates the increase in unemployment. The extent to which actual wages vary cyclically remains an open and important question. Our results suggest that any such wage rigidity cannot be justified by mechanisms that appeal to aspects of the opportunity cost.

We illustrate the consequences of a procyclical $z$ in the context of two leading proposed solutions to the unemployment volatility puzzle that rely on endogenous wage rigidity. Hagedorn and Manovskii (2008) show that a large and constant $z$ allows the Mortensen-Pissarides model with Nash wage bargaining to generate realistic unemployment fluctuations. Intuitively, a level of $z$ close to the tax-adjusted $p$ makes the total surplus from an employment relationship small on average. Then even modest increases in $p$ generate large percentage increases in the surplus, incentivizing firms to significantly increase their job creation. ${ }^{2}$ However, if $z$ and $p$ move proportionally, then the surplus from a new hire remains relatively stable over the business cycle. As a result, fluctuations in unemployment are essentially neutral with respect to the level of $z$.

${ }^{2}$ A number of papers have followed this reasoning to set a relatively high level of $z$. Hagedorn and Manovskii (2008) use a value of $z=0.955$. Examples of papers before Hagedorn and Manovskii (2008) include Mortensen and Pissarides (1999, 2001), Hall (2005), and Shimer (2005), which set $z$ at $0.42,0.51,0.40$, and 0.40 . Examples of papers after Hagedorn and Manovskii (2008) include Mortensen and Nagypal (2007), Costain and Reiter (2008), Hall and Milgrom (2008), and Bils, Chang, and Kim (2012), which set $z$ at $0.73,0.745,0.71$, and 0.82 . See Hornstein, Krusell, and Violante (2005) for a useful summary of this literature. 
Hall and Milgrom (2008) generate volatile unemployment fluctuations by replacing the assumption of Nash bargaining over match surplus with an alternating-offer wage-setting mechanism. With Nash bargaining, the threat point of an unemployed depends on the wage other jobs would offer in case of bargaining termination. In the alternating-offer bargaining game, the threat point depends instead mostly on the flow value $z$ if bargaining continues. With constant $z$, wages respond weakly to increases in $p$. Instead allowing $z$ to comove with $p$ as in the data undoes this endogenous wage rigidity, thereby reducing the volatility of unemployment.

Finally, we show that $z$ plays an important role in equilibrium models outside of the Mortensen-Pissarides class. We discuss models with directed search and indivisible labor. The same expression for $z$ enters into the opportunity cost of employment in each of these models and therefore plays an important role in determining unemployment fluctuations.

\section{The Opportunity Cost of Employment}

We develop an expression for the opportunity cost of employment $z$ within a widely studied framework that borrows elements from the search and matching model and the RBC model with concave preferences and a positive value of nonworking time. In Section VII.A, we show that $z$ is a key object for understanding equilibrium unemployment within this standard Mortensen-Pissarides/RBC model. However, as we discuss below, the same $z$ arises in alternative models that relax many of the baseline assumptions embedded in the Mortensen-Pissarides/RBC model.

\section{A. Household Problem}

Time is discrete and the horizon is infinite, $t=0,1,2, \ldots$ We denote the vector of exogenous aggregate shocks by $\mathbf{Z}_{t}$. All values are expressed in terms of a numeraire good with a price of one.

A representative household consists of a continuum of ex ante identical individuals of measure one. At the beginning of each period $t$, there are $e_{t}$ employed who produce output and $u_{t}=1-e_{t}$ unemployed who search for jobs. After production occurs, unemployed find a job in the next period with probability $f_{t}$ and employed separate and become unemployed with probability $s_{t}$. Therefore, employment evolves according to the law of motion:

$$
e_{t+1}=\left(1-s_{t}\right) e_{t}+f_{t} u_{t} .
$$

Household members treat $f_{t}$ and $s_{t}$ as exogenous processes.

The household takes as given employment $e_{t}$ at the beginning of each period and the outcome of any process that determines the wage $w_{t}$ and 
hours per worker $N_{t}$. Household members pool perfectly their risks, and therefore, the marginal utility of consumption $\lambda_{t}$ is equalized between the employed and the unemployed. The household owns the economy's capital stock $K_{t}$ and rents it to firms at a rate $r_{t}+\delta$, where $r_{t}$ denotes the real interest rate and $\delta$ denotes the depreciation rate. Capital $K_{t}$ accumulates as $K_{t+1}=(1-\delta) K_{t}+I_{t}$.

The household chooses consumption of the employed and the unemployed, $C_{t}^{e}$ and $C_{t}^{u}$, purchases of investment goods $I_{t}$, and the share of eligible unemployed to take up UI benefits, $\zeta_{t}$, to maximize the expected sum of discounted utility flows of its members:

$$
\begin{aligned}
W^{h}\left(e_{0}, \omega_{0}, K_{0}, \mathbf{Z}_{0}\right)= & \max \mathbb{E}_{0} \sum_{t=0}^{\infty} \beta^{t}\left[e_{t} U\left(C_{t}^{e}, N_{t}\right)+\left(1-e_{t}\right) U\left(C_{t}^{u}, 0\right)\right. \\
& \left.-\left(1-e_{t}\right) \omega_{t} \psi\left(\zeta_{t}\right)\right],
\end{aligned}
$$

where $U\left(C_{t}^{e}, N_{t}\right)$ is the flow utility of an employed member, $U\left(C_{t}^{u}, 0\right)$ is the flow utility of an unemployed member excluding costs associated with taking up benefits, $\omega_{t}$ is the share of unemployed who are eligible for UI benefits, and $\psi\left(\zeta_{t}\right)$ denotes the household's costs per eligible unemployed from taking up UI benefits.

The budget constraint of the household is given by

$$
\begin{aligned}
& \left(1+\tau_{t}^{C}\right)\left[e_{t} C_{t}^{e}+\left(1-e_{t}\right) C_{t}^{u}\right]+I_{t}+\Pi_{t} \\
= & \left(1-\tau_{t}^{w}\right) w_{t} e_{t} N_{t}+\left(1-e_{t}\right) B_{t}+\left(r_{t}+\delta\right) K_{t},
\end{aligned}
$$

where $B_{t}$ denotes after-tax benefits received per unemployed, $\tau_{t}^{C}$ is the tax rate on consumption, and $\tau_{t}^{w}$ is the tax rate on labor income. We denote by $\Pi_{t}$ the sum of lump-sum taxes and the consumption of individuals out of the labor force net of dividends from ownership of the firms and other transfers.

\section{Benefits}

Benefits $B_{t}$ received from the government may include after-tax UI benefits as well as other transfers such as supplemental nutritional assistance, welfare assistance, and health care. The term $B_{t}$ includes only the part of the benefit that an unemployed loses upon moving to employment. ${ }^{3}$ We split $B_{t}$ into two components. Non-UI benefits per unemployed, $B_{n, t}$, do

\footnotetext{
${ }^{3}$ Benefits that do not depend on labor force status do not affect the value of unemployment relative to employment and are included in the variable $\Pi_{t}$. These benefits include the part of transfers such as supplemental nutritional assistance that do not depend on employment status and programs such as disability insurance that accrue only to those out of the labor force.
} 
not involve take-up costs in our model because the decision and timing of take-up do not generally coincide with the timing of an unemployment spell. Additionally, non-UI benefits do not generally generate tax liabilities. UI benefits per unemployed, $B_{u, t}$, have a relevant take-up margin and have been taxed at the federal level since 1979. We write after-tax benefits per unemployed as

$$
B_{t}=\left(1+\tau_{t}^{C}\right) B_{n, t}+\left(1-\tau_{t}^{B}\right) B_{u, t},
$$

where $\tau_{t}^{B}$ is the tax rate on UI benefits. We multiply non-UI benefits by $1+$ $\tau_{t}^{C}$ because most of $B_{n, t}$, including nutrition assistance and Medicaid, is not subject to consumption taxes. Therefore, a unit of these benefits is worth $1+\tau_{t}^{C}$ units of (taxable) consumption.

We introduce utility costs of UI take-up into the objective function (2) of the household in order to account for a take-up rate $\zeta_{t}$ that in the data is significantly below one, is volatile, and comoves with the benefit level. ${ }^{4}$ The fact that some of those eligible forgo their UI entitlement indicates either an informational friction or a take-up cost. The correlation between take-up and benefits suggests that informational frictions cannot fully explain the low take-up rate. We interpret these utility costs as forgone time and effort associated with searching for a job and providing information to the UI agency. We consider an alternative model of takeup without utility costs in our robustness exercises.

The household's total cost per eligible unemployed $\psi_{t}$ depends on the fraction of those eligible that take up UI benefits $\zeta_{t}$. To see how such a dependence may arise, let $\psi^{m}(i)$ denote the cost of UI take-up by the $i \in[0,1]$ eligible unemployed. We order the heterogeneous costs as $\mathrm{d} \psi^{m} / \mathrm{d} i>0$. If a fraction $\zeta_{t}$ of eligible unemployed choose to take up benefits, then the total utility cost of taking up benefits per eligible unemployed is

$$
\psi\left(\zeta_{t}\right)=\int_{0}^{\zeta_{t}} \psi^{m}(i) \mathrm{d} i
$$

The cost function $\psi\left(\zeta_{t}\right)$ is increasing and convex because as $\zeta_{t}$ increases, the marginal recipient has a higher utility cost. A convex cost function $\psi\left(\zeta_{t}\right)$ guarantees an interior solution for $\zeta_{t}$. In the empirical analysis below, we find evidence of convexity in the data.

Pretax benefits per unemployed from UI, $B_{u, t}$ are the product of the fraction of unemployed who are eligible for benefits $\omega_{t}$, the fraction of

\footnotetext{
${ }^{4}$ Blank and Card (1991) find that roughly one-third of unemployed eligible for UI do not claim benefits and provide state-level evidence that the take-up rate responds to benefit levels (see also Anderson and Meyer 1997). We find significant fluctuations in the take-up rate over the business cycle, and these fluctuations are systematically related to fluctuations in the utility value of benefits.
} 
eligible unemployed who take up benefits $\zeta_{t}$, and benefits per recipient unemployed $\widetilde{B}_{t}, B_{u, t}=\omega_{t} \zeta_{t} \tilde{B}_{t}=\phi_{t} \tilde{B}_{t}$, where $\phi_{t}=\omega_{t} \zeta_{t}$ is the fraction of unemployed receiving UI. The fraction of eligible unemployed $\omega_{t}$ is a state variable that depends on past eligibility, expiration policies, and the composition of the newly unemployed. In the United States, UI eligibility depends on sufficient earnings during previous employment (monetary eligibility), the reason for employment separation (nonmonetary eligibility), and the number of weeks of UI already claimed (expiration eligibility). We model expiration eligibility with a simple process under which eligible unemployed who do not find a job in period $t$ maintain their eligibility in period $t+1$ with an exogenous probability $\omega_{t+1}^{u}$. We combine monetary and nonmonetary eligibility into a single term $\omega_{t+1}^{e}$, which gives the exogenous probability that a newly unemployed in period $t$ is eligible for UI in the next period. The stock of eligible unemployed in period $t+1$ is $u_{t+1}^{E}=\omega_{t+1}^{u}\left(1-f_{t}\right) u_{t}^{E}+\omega_{t+1}^{e} s_{t} e_{t}$. Therefore, the fraction of eligible unemployed $\omega_{t+1}=u_{t+1}^{E} / u_{t+1}$ follows the law of motion:

$$
\omega_{t+1}=\left[\omega_{t+1}^{u}\left(1-f_{t}\right) \frac{u_{t}}{u_{t+1}}\right] \omega_{t}+\omega_{t+1}^{e} s_{t} \frac{e_{t}}{u_{t+1}} .
$$

\section{First-Order Conditions}

Denoting by $\lambda_{t} /\left(1+\tau_{t}^{C}\right)$ the multiplier on the budget constraint, the first-order conditions for household optimization are

$$
\begin{gathered}
\lambda_{t}=\frac{\partial U_{t}^{e}}{\partial C_{t}^{e}}=\frac{\partial U_{t}^{u}}{\partial C_{t}^{u}}, \\
\frac{\lambda_{t}}{1+\tau_{t}^{C}}=\mathbb{E}_{t} \beta\left(\frac{\lambda_{t+1}}{1+\tau_{t+1}^{C}}\right)\left(1+r_{t+1}\right), \\
\psi^{\prime}\left(\zeta_{t}\right)=\left(\frac{1-\tau_{t}^{B}}{1+\tau_{t}^{C}}\right) \lambda_{t} \tilde{B}_{t} .
\end{gathered}
$$

Equation (7) is the risk-sharing condition, requiring that the household allocates consumption to different members to equate their marginal utilities. Equation (8) is the Euler equation. Equation (9) is the first-order condition for the optimal take-up rate $\zeta_{t}$. Eligible unemployed claim benefits up to the point where the marginal cost $\psi^{\prime}\left(\zeta_{t}\right)$ equals the utility value of after-tax benefits $\left(1-\tau_{t}^{B}\right) /\left(1+\tau_{t}^{C}\right) \lambda_{t} \tilde{B}_{t}$. From equation (5), the marginal cost for the household $\psi^{\prime}\left(\zeta_{t}\right)$ equals the utility cost of the marginal recipient $\psi^{m}\left(\zeta_{t}\right)$. If $\psi^{\prime \prime}\left(\zeta_{t}\right)>0$, then a higher utility value of after-tax benefits incentivizes eligible unemployed with higher utility costs to take up benefits and $\zeta_{t}$ increases. 


\section{B. Derivation of the Opportunity Cost of Employment}

A key object in models of equilibrium unemployment is the marginal value that the household attaches to an additional employed, $J_{t}^{h}=$ $\partial W^{h}\left(e_{t}, \omega_{t}, K_{t}, \mathbf{Z}_{t}\right) / \partial e_{t}$. This value reflects the willingness of the household to supply labor along the extensive margin. We express the marginal value in consumption units by dividing it by the marginal utility of consumption $\lambda_{i}$ :

$$
\begin{aligned}
\frac{J_{t}^{h}}{\lambda_{t}}= & \left(\frac{1-\tau_{t}^{w}}{1+\tau_{t}^{C}}\right) w_{t} N_{t}-\underbrace{\left[b_{t}+\left(C_{t}^{e}-C_{t}^{u}\right)-\frac{U_{t}^{e}-U_{t}^{u}}{\lambda_{t}}\right]}_{z_{t}=b_{t}+\xi_{t}} \\
& +\left(1-s_{t}-f_{t}\right) \mathbb{E}_{t}\left(\frac{\beta \lambda_{t+1}}{\lambda_{t}}\right) \frac{J_{t+1}^{h}}{\lambda_{t+1}} .
\end{aligned}
$$

Online appendix A.1 presents details underlying the derivation of equation (10) and other results in this section.

The marginal value of an employed in terms of consumption consists of a flow value plus the expected discounted marginal value in the next period. The expected discounted marginal value appears in equation (10) because employment is a state variable, and therefore, an employment relationship created in period $t$ is expected to also yield value in future periods.

The flow component of $J_{t}^{h}$ consists of a flow gain from increased aftertax wage income, $w_{t} N_{t}\left(1-\tau_{t}^{w}\right) /\left(1+\tau_{t}^{C}\right)$, and a flow loss, $z_{t}$, associated with moving an individual from unemployment to employment. Following Hall and Milgrom (2008), we define the (flow) opportunity cost of employment, $z_{t}$, as the bracketed term in equation (10). We split $z_{t}$ into two components, with $b_{t}$ denoting the component related to forgone benefits and $\xi_{t}=z_{t}-b_{t}$ denoting the component related to the forgone value of nonworking time.

Before discussing each component of $z$ in further detail, we pause to make two comments. First, the $z$ defined in equation (10) is an average across unemployed individuals. Heterogeneity in benefit eligibility and take-up costs generates dispersion in the opportunity cost of individual unemployed. We follow Mortensen and Nagypal (2007) and justify the aggregation by assuming that employers cannot discriminate ex ante in choosing a potential worker with whom to bargain. Therefore, even if unemployed have heterogeneous opportunity costs, the vacancy creation decision of firms depends on the average opportunity cost over the set of unemployed. This makes the average $z$ the relevant object for labor market fluctuations. 
Second, our measurement of $z$ proceeds directly from the bracketed term in equation (10). That is, our approach imposes the minimum structure necessary to derive $z$ as a function of observable variables in the data (e.g., consumption, hours, benefits, and take-up rates) and preference parameters. Measurement of $z$ then does not require specifying what model generates these variables. We take this minimalist approach because $z$ is an important object in many models of the labor market.

\section{Opportunity Cost of Employment: Benefits}

The opportunity cost of employment related to benefits is given by

$$
\begin{aligned}
b_{t}= & B_{n, t}+B_{u, t}\left(\frac{1-\tau_{t}^{B}}{1+\tau_{t}^{C}}\right)\left(1-\frac{1}{\alpha}\right) \\
& \times\left\{1-\mathbb{E}_{t}\left[\frac{\beta \lambda_{t+1}\left(\frac{1-\tau_{t+1}^{B}}{1+\tau_{t+1}^{C}}\right) \tilde{B}_{t+1} \zeta_{t+1}}{\lambda_{t}\left(\frac{1-\tau_{t}^{B}}{1+\tau_{t}^{C}}\right) \tilde{B}_{t} \zeta_{t}}\right]\left(\frac{\omega_{t+1}^{e}}{\omega_{t}}-\omega_{t+1}^{u}\right) \Gamma_{t+1}\right\},
\end{aligned}
$$

where $\alpha=\psi^{\prime}\left(\zeta_{t}\right) \zeta_{t} / \psi\left(\zeta_{t}\right)>1$ and

$$
\Gamma_{t+1}=\left[\frac{s_{t}\left(1-f_{t}\right)}{1-e_{t+1}}\right]\left[1-\frac{\beta \lambda_{t+1}\left(1+\tau_{t}^{C}\right)}{\lambda_{t}\left(1+\tau_{t+1}^{C}\right)} \omega_{t+1}^{u}\left(1-f_{t}\right) \frac{u_{t}}{u_{t+1}}\right]^{-1}>0 .
$$

The first term in equation (11) for $b_{t}$ is simply non-UI benefits per unemployed, $B_{n, t}$. The second term consists of pretax UI benefits per unemployed $B_{u, t}$, multiplied by the tax wedge $\left(1-\tau_{t}^{B}\right) /\left(1+\tau_{t}^{C}\right)$, an adjustment for the disutility of take-up $1-(1 / \alpha)$, and an adjustment for benefits expiration (the term in braces).

The term $1-(1 / \alpha)<1$ in equation (11) captures the fact that, because of take-up costs, the utility value from receiving UI benefits is lower than the monetary value of UI benefits. The average utility value per recipient equals the benefit per recipient less the average utility cost per recipient, $\left(1-\tau_{t}^{B}\right) \lambda_{t} \tilde{B}_{t} /\left(1+\tau_{t}^{C}\right)-\psi\left(\zeta_{t}\right) / \zeta_{t}$. Using the first-order condition (9), the average utility value is equivalently given by the difference between the marginal and the average cost, $\psi^{\prime}\left(\zeta_{t}\right)-\psi\left(\zeta_{t}\right) / \zeta_{t}$. This difference depends on the elasticity of the cost function $\alpha=\psi^{\prime}\left(\zeta_{t}\right) \zeta_{t} / \psi\left(\zeta_{t}\right)$. With a convex $\psi\left(\zeta_{t}\right)$ function, we have $\alpha>1$. If the elasticity $\alpha$ is close to one, average cost per recipient is roughly constant and there is a small utility value from receiving benefits as the household always incurs a cost per recipient that approximately equals the benefit per recipient. The greater the elasticity $\alpha$, the lower the average relative to the marginal cost 
per recipient and the larger the utility value that the household receives from benefits.

The term in braces in equation (11) captures an adjustment for the expiration of UI benefits. This term is less than one when the probability that newly separated workers receive benefits, $\omega_{t+1}^{e}$, exceeds the probability that previously eligible workers continue to receive benefits, $\omega_{t+1}^{u} \omega_{t}$. Intuitively, increasing employment in the current period entitles workers to future benefits, which lowers the opportunity cost of employment. The term $\Gamma_{t+1}$ partly captures the dynamics of this effect over time, since increasing employment in the current period affects the whole path of future eligibility.

\section{Opportunity Cost of Employment: Value of Nonworking Time}

The second component of the opportunity cost of employment, $\xi$, results from consumption and work differences between employed and unemployed. It is useful to write it as

$$
\xi_{t}=\frac{\left[U\left(C_{t}^{u}, 0\right)-\lambda_{t} C_{t}^{u}\right]-\left[U\left(C_{t}^{e}, N_{t}\right)-\lambda_{t} C_{t}^{e}\right]}{\lambda_{t}} .
$$

The first term in the numerator, $U\left(C_{t}^{u}, 0\right)-\lambda_{t} C_{t}^{u}$, is the total utility of the unemployed less the utility of the unemployed from consumption. It has the interpretation of the utility the unemployed derive solely from nonworking time. Similarly, the term $U\left(C_{t}^{e}, N_{t}\right)-\lambda_{t} C_{t}^{e}$ represents the utility of the employed from nonworking time. The difference between the two terms represents the additional utility the household obtains from nonworking time when moving an individual from employment to unemployment. The denominator of $\xi_{t}$ is the common marginal utility of consumption. Therefore, $\xi_{t}$ represents the value of nonworking time in units of consumption.

The expression for $\xi_{t}$ resembles the marginal rate of substitution between nonworking time and consumption in the RBC model, with the difference being that the additional value of nonworking time is calculated along the extensive margin. As in the RBC model, $\xi_{t}$ is procyclical. First, when $\lambda_{t}$ rises in recessions, the value of earning income that can be used for consumption rises relative to the value of nonworking time. Second, $N_{t}$ gives the difference in nonworking time between the unemployed and the employed. When $N_{t}$ falls in recessions, the contribution of the unemployed relative to the employed to household utility declines. In sum, the household values more the contribution of the employed (who generate higher wage income) relative to that of the unemployed (who have higher nonworking time) during recessions, when 
consumption is lower and the difference in nonworking time between employed and unemployed is smaller.

\section{Comparison to the Mortensen-Pissarides Literature}

The Mortensen-Pissarides literature typically assumes a constant $z_{t}=z$. If the value of benefits does not fluctuate, $b_{t}=b$, then $z_{t}$ is constant if $\xi_{t}$ is constant. We describe two sets of restrictions on utility that generate a constant $\xi$ :

1. no disutility from hours worked and utility functions that do not depend on employment status (e.g., Shimer 2005):

$$
U_{t}^{s}=U\left(C_{t}^{s}\right), s \in\{e, u\} \Rightarrow C_{t}^{e}=C_{t}^{u}, U_{t}^{e}=U_{t}^{u} \Rightarrow \xi_{t}=0 \Rightarrow z_{t}=b .
$$

2. linearity in consumption, separability, and constant hours per worker $N$ (e.g., Hagedorn and Manovskii 2008):

$$
U_{t}^{e}=C_{t}^{e}-v(N), U_{t}^{u}=C_{t}^{u} \Rightarrow \xi_{t}=v(N) \Rightarrow z_{t}=b+v(N) .
$$

In general, the component $\xi_{t}$ will vary over time if $N_{t}$ enters as an argument into the utility function and either (i) $N_{t}$ varies over time or (ii) utility is not linear in consumption.

\section{Comparison to Other Models}

Our baseline model adopts assumptions from the household block of the standard Mortensen-Pissarides/RBC model. The broad popularity of this model as well as its analytical elegance make it the natural starting point for analyzing $z .{ }^{5}$ However, the same $z$ defined in equation (10) arises in other contexts. To make this point clear, we highlight four assumptions of the benchmark model, which we later relax or change:

\footnotetext{
${ }^{5}$ Our model follows much of the literature in abstracting from the labor force participation margin. This abstraction omits potentially important flows into and out of participation and affects our measurement insofar as people move directly from nonparticipation to employment. Allowing for endogenous labor force participation would not, however, affect our expression for $z$. For example, allowing nonemployed workers to choose between unemployment and nonparticipation would add a first-order condition to the model requiring indifference between the two states. The marginal value of adding an employed would still be given by eq. (10).
} 
1. Ex ante homogeneous workers: Section VI applies our measurement exercise to heterogeneous groups defined along observable characteristics.

2. Wage-setting mechanism: Sections VII.A and VII.B illustrate how $z$ affects equilibrium unemployment under Nash bargaining and alternating-offer wage bargaining, respectively.

3. Random search: Section VII.C shows that $z$ plays an equivalent role in a model with directed search and wage posting.

4. Employment as a state variable: Section VII.D derives the same $z$ in the indivisible labor model of Hansen (1985) and Rogerson (1988) in which households can freely adjust employment at any point of time.

Finally, in online appendix $\mathrm{C}$ we derive a closely related measure of the opportunity cost in a model with incomplete asset markets.

\section{Measurement of the $b$ Component}

In this section we use equation (11) to generate a time series of $b$. We depart from the literature in three significant ways. First, following the aggregation logic outlined above, we measure the average benefit across all unemployed rather than statutory benefit rates. This matters because, on average, only about 40 percent of unemployed actually receive UI. Second, the social safety net includes a number of other programs such as supplemental nutritional assistance payments (SNAP, formerly known as food stamps), welfare assistance (Temporary Assistance for Needy Families [TANF], formerly Aid to Families with Dependent Children [AFDC] ), and health care (Medicaid). Income from all of these programs belongs in $B_{n, t}$ to the extent that unemployment status correlates with receipt of these benefits. Third, for UI benefits we differentiate between monetary benefits per unemployed $B_{u, t}$ and the part of these benefits associated with the opportunity cost of employment. As equation (11) shows, the latter deviate from $B_{u, t}$ because of taxes, utility costs associated with taking up benefits, and expiration.

For our measurement of $b$ we require time series of variables such as benefits, eligibility and take-up rates, separation and job-finding rates, and taxes. We construct such a data set drawing on microdata from the CPS, SIPP, and IRS Public Use Files; published series from the NIPA, Bureau of Labor Statistics (BLS), and various other government agencies; and historical data collected from print issues of the Economic Report of the President. Online appendix B.1 provides greater detail on the source data. 


\section{A. Benefits per Unemployed}

We begin by measuring non-UI benefits per unemployed, $B_{n, t}$, and UI benefits per unemployed, $B_{u, t}$, in equation (11). Our empirical approach to measuring the monetary value of benefits combines micro survey data with program administrative data. Let $B_{k, t}$ denote benefits per unemployed in each program $k \in\{\mathrm{UI}, \mathrm{SNAP}, \mathrm{AFDC} / \mathrm{TANF}, \mathrm{Medicaid}\} .{ }^{6} \mathrm{We}$ measure $B_{k, t}$ as

$$
\begin{aligned}
B_{k, t}= & {\left[\frac{(\text { survey dollars tied to unemployment status })_{k, t}}{(\text { total survey dollars })_{k, t}}\right] } \\
& \times\left[\frac{(\text { total administrative dollars })_{k, t}}{(\text { number of unemployed })_{t}}\right] .
\end{aligned}
$$

We use the microdata to estimate the term in the first brackets in equation (13), the fraction of total program spending in the survey that depends on unemployment status, and call this ratio $B_{k, t}^{\text {share }}$. We then multiply $B_{k, t}^{\text {share }}$ by the ratio of dollars from program administrative data to the number of unemployed (the term in the second brackets). We adjust the survey estimate of dollars tied to unemployment status by the ratio of administrative to survey dollars to correct for the fact that program benefits in surveys are underreported (Meyer, Mok, and Sullivan 2009).

We now explain and implement our procedure to estimate $B_{k, t}^{\text {share }}$. Define $y_{k, i, t}$ as income from category $k$ received by household or person $i$. We use the microdata to estimate the change in $y_{k, i, t}$ following an employment status change. To solve the time aggregation problem that arises because an individual may spend part of the reporting period employed and part unemployed, we model directly the instantaneous income of type $k$ for an individual with labor force status $s \in\{e, u\}$. This is given by

$$
y_{k, i, t}^{s}=\phi_{k} \mathbf{X}_{i}+y_{k, t}^{e}+\beta_{k, t} \mathbb{I}\left\{s_{i, t}=u\right\}+\epsilon_{k, i, t},
$$

where $\mathbf{X}_{i}$ denotes a vector of individual characteristics, $y_{k, t}^{e}$ is a base income level of an employed, and $\mathbb{I}\left\{s_{i, t}=u\right\}$ is an indicator function taking the value of one if the individual is unemployed at time $t$. According to this process, income from program $k$ increases discretely by $\beta_{k, t}$ during an unemployment spell. Integrating over the reporting period and taking first differences to eliminate the individual fixed effect yields

$$
\Delta y_{k, i, t}=\beta_{k, t}^{0}+\beta_{k, t} \Delta D_{i, t}^{u}+\Delta \beta_{k, t} D_{i, t-1}^{u}+\Delta \epsilon_{k, i, t},
$$

\footnotetext{
${ }^{6}$ We also investigated the importance of housing subsidies. We found their importance quantitatively trivial and therefore omit them from the analysis.
} 
where $\beta_{k, t}^{0}=\Delta y_{k, t}^{e}$ and the variable $D_{i, t}^{u}$ measures the fraction of the reporting period that an individual spends as unemployed.

By definition, $B_{k, t}^{\text {share }}$ is

$$
\begin{aligned}
B_{k, t}^{\text {share }} & =\frac{(\text { survey dollars tied to unemployment status })_{k, t}}{(\text { total survey dollars })_{k, t}} \\
& =\beta_{k, t} \frac{\sum_{i} \omega_{i, t} D_{i, t}^{u}}{\sum_{i} \omega_{i, t} y_{k, i, t}}
\end{aligned}
$$

where $\omega_{i, t}$ is the survey sampling weight for individual $i$ in period $t$. Substituting equation (16) into equation (15) gives a direct estimate of $B_{k, t}^{\text {share }}$ from the regression

$$
\Delta y_{k, i, t}=\beta_{k, t}^{0}+B_{k, t}^{\mathrm{share}} \Delta \tilde{D}_{i, t}+\Delta \beta_{k, t} D_{i, t-1}^{u}+\Delta \epsilon_{k, i, t},
$$

where

$$
\Delta \tilde{D}_{i, t}=\Delta D_{i, t}^{u} \sum_{i} \omega_{i, t} y_{k, i, t} / \sum_{i} \omega_{i, t} D_{i, t}^{u}
$$

We implement equation (17) using both the March CPS with households matched across consecutive years starting in 1989 and the SIPP starting in 1996. Appendix B.1 describes the surveys and our sample construction. In each survey, we construct a measure of unemployment at the individual level that mimics the BLS U-3 definition. The U-3 definition of unemployment counts an individual as working if he had a job during the week containing the twelfth of the month (the survey reference week) and as in the labor force if he worked during the reference week, spent the week on temporary layoff, or had any search in the previous 4 weeks. $^{7}$

We aggregate unemployment and income up to the level at which the benefits program is administered. In particular, in the regressions with UI income as the dependent variable, the unit of observation is the individual, and we cluster standard errors at the household level. In regressions for SNAP, TANF, and Medicaid, the unit of observation is the family average of unemployment and the family total of income. Finally, for each benefit category we exclude observations with imputed benefit amounts in that category.

${ }^{7}$ In the March supplement, we count an individual as in the labor force during the previous year only for those weeks in which the individual reports working, being on temporary layoff, or actually searching. In the SIPP, we count an individual as employed if he worked in any week of the month rather than only if he worked during the BLS survey reference week. Accordingly, we define the fraction of time an individual is unemployed as

$$
\begin{aligned}
D_{i, t}^{u, \mathrm{CPS}} & =\left(\frac{\text { weeks searching or on temporary layoff in year } t}{\text { weeks in the labor force in year } t}\right), \\
D_{i, t}^{u, \mathrm{SIPP}} & =\frac{1}{4} \sum_{m=1}^{4} \mathbb{I}\left\{(\text { nonemployed, at least } 1 \text { week of search or layoff })_{i, t-m}\right\} .
\end{aligned}
$$


Table 1 reports results based on ordinary least squares (OLS) regressions of equation (17) that constrain $B_{k, t}^{\text {share }}$ to be constant over time. ${ }^{8}$ For UI, the average $B^{\text {share }}$ is 0.916 . If only unemployed persons received UI, then this share would have been equal to one. In fact, in many states individuals with part-time unemployment can retain eligibility for UI, and some individuals report claiming UI without exerting any search effort. Our estimate of the share of UI income accruing to nonunemployed is 8.4 percent. This estimate accords well with audits conducted by the Department of Labor, which find that roughly 10 percent of UI payments go to ineligible recipients.

Only roughly 5 percent of SNAP and TANF and 2 percent of Medicaid spending appear in $B_{n, t}$. We find these estimates reasonable. Roughly two-thirds of Medicaid payments accrue to persons who are over 65, blind, or disabled Centers for Medicare and Medicaid Services 2011 data, table II.4). Moreover, even prior to implementation of the Affordable Care Act, all states had income limits for coverage of children of at least 100 percent of the poverty line, and half of states provided at least partial coverage to working adults with incomes at the poverty line (2013 data from the Kaiser Family Foundation).$^{9}$ For SNAP, tabulations from the monthly quality control files provided by Mathematica indicate that no more than one-quarter of SNAP benefits go to households with at least one member unemployed. Given statutory phase-out rates and deductions, 5 percent appears as a reasonable estimate.

To summarize, in order to measure $B_{n, t}$ and $B_{u, t}$ we first use micro survey data to estimate the share of each program's total spending associated with unemployment, $B_{k}^{\text {share }}$. We then apply this share to the total spending observed in administrative data. As a result, $B_{n, t}$ and $B_{u, t}$ inherit directly the cyclical properties of the program administrative data. Although the $B_{k}^{\text {share }}$ 's for the non-UI programs are small, the standard errors strongly indicate that they are not zero. We plot the resulting time series of $B_{n, t}$ and $B_{u, t}$ in constant 2009 dollars in figure 1.

\section{B. Eligibility, Take-Up Rate, and UI Recipients}

We continue our analysis by constructing other terms that enter $b$ in equation (11). Consistent with our unemployment variable (BLS series

${ }^{8}$ We find that the correlation between the cyclical component of an estimated timevarying $B_{k, t}^{\text {share }}$ and the cyclical component of the unemployment rate is, on average (across programs $k$ and surveys), equal to .07 .

9 Data for the Centers for Medicare and Medicaid Services are available at https:// www.cms.gov/Research-Statistics-Data-and-Systems /Statistics-Trends-and-Reports /DataCompendium/2011_Data_Compendium.html. Data for the Kaiser Family Foundation are available at https://kaiserfamilyfoundation.files.wordpress.com/2013/04/7993 -03.pdf. 
TABLE 1

Share of Government Program Benefits Belonging to $B$

\begin{tabular}{lcccc}
\hline \hline & UI & SNAP & TANF & Medicaid \\
\hline CPS (1989-2013): & & & & \\
$B^{\text {share }}$ & .909 & .064 & .065 & .021 \\
Observations & $(.020)$ & $(.005)$ & $(.011)$ & $(.003)$ \\
SIPP (1996-2013): & 483,686 & 273,731 & 318,611 & 268,689 \\
$\quad B^{\text {share }}$ & .923 & .048 & .033 & \\
Observations & $(.015)$ & $(.002)$ & $(.005)$ & \\
Mean of $B^{\text {share }}$ (CPS and SIPP) & $1,560,244$ & $1,000,914$ & $1,027,545$ & \\
\hline
\end{tabular}

Note.-The table reports summary statistics based on OLS regressions of eq. (17), where $B^{\text {share }}$ is defined in eq. (16). The regressions exclude observations with imputed income in the category and are weighted using sampling weights in each year, with the weights normalized such that all years receive equal weight. Standard errors (in parentheses) are based on heteroskedastic robust (CPS, non-UI), heteroskedastic robust and clustered by family (CPS, UI), or heteroskedastic robust and clustered by household (SIPP) variance matrix.

LNS13000000), the number of employed comes from the monthly CPS (BLS series LNS12000000). With a constant labor force, the number of newly unemployed workers equals the product of the previous period's separation rate $s_{t-1}$ and stock of employed workers $e_{t-1}$. We therefore define the separation rate $s_{t}$ at a quarterly frequency as the ratio of the number of workers unemployed for fewer than 15 weeks in quarter $t+$ 1 (using the sum of BLS series LNS13008397 and LNS13025701) to the

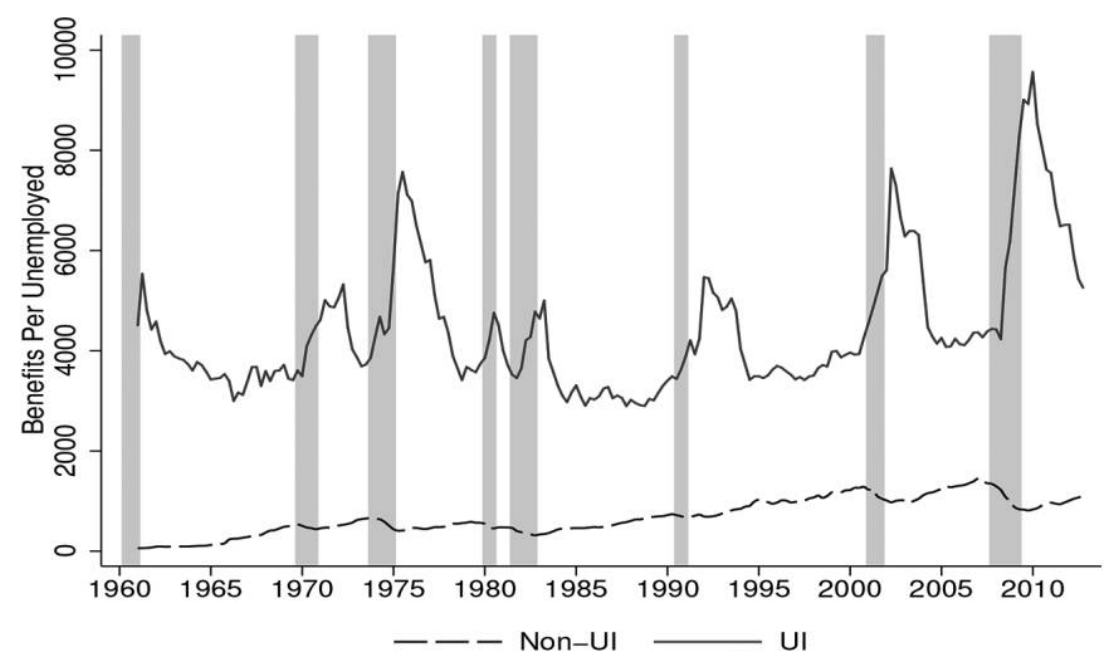

FIG. 1.-Time series of benefits per unemployed. The figure reports UI and non-UI benefits per unemployed in constant 2009 dollars. Color version available as an online enhancement. 
number of employed workers in $t$. The separation rate and the unemployment rate allow us to calculate the job-finding rate $f_{t}$ from the law of motion for unemployment $u_{t+1}=u_{t}\left(1-f_{t}\right)+s_{t}\left(1-u_{t}\right) \cdot{ }^{10}$

We next construct estimates of UI benefits per recipient $\tilde{B}_{t}$, the fraction of unemployed receiving UI benefits $\phi_{t}$, the fraction of eligible unemployed $\omega_{t}$, and the fraction of eligible who take up benefits $\zeta_{t}$. The Department of Labor provides data on the number of UI recipients in all tiers (state regular benefits, extended benefits, and federal emergency benefits) beginning in 1986. We extend this series back to 1961 using data from statistical appendix B of the Economic Report of the President. Dividing the NIPA total of UI benefits paid (table 2.6, line 21) by the number of UI recipients gives a time series of UI benefits per recipient $\tilde{B}_{t}$. The fraction of unemployed receiving benefits is $\phi_{t}=B_{u, t} / \tilde{B}_{t}$, where $B_{u, t}$ is our estimate of UI benefits per unemployed from Section III.A.

We estimate $\omega_{t}$ from its law of motion in equation (6) and data on $u_{t}, s_{t}$, $f_{t}, \omega_{t}^{e}$, and $\omega_{t}^{u}$. We measure the probability that a newly unemployed is eligible for UI, $\omega_{t}^{e}$, using the fact that workers who quit their jobs and new labor force entrants are ineligible for UI. From the CPS basic monthly microdata, we measure the unemployed for less than 5 weeks who report "job loser" as their reason for unemployment. We add to this total the product of the number of reentrants who have worked in the past 12 months and the 6-month lag of the fraction of job losers among those moving from employment to unemployment. Dividing by the total number of unemployed for less than 5 weeks gives an estimate of the fraction of the newly unemployed that satisfy nonmonetary eligibility. We tie cyclical movements in $\omega_{t}^{e}$ to cyclical movements in this fraction. ${ }^{11}$ We center $\omega_{t}^{e}$ around 0.75 to target a mean take-up rate $\zeta_{t}$ of 0.65 .

We set $\omega_{t}^{u}$, the probability that an unemployed remains eligible, such that the expected potential duration of eligibility equals the national maximum of weeks eligible, adjusted for the fact that not every unemployed individual has the maximal potential duration (see app. B.1 for

\footnotetext{
${ }^{10}$ We recognize the point of Shimer (2012) that this procedure understates the amount of gross flows between unemployment and employment because some workers separate and find a new job within the period. A discrete time calibration must accept this shortcoming if both the law of motion for unemployment holds and the share of newly unemployed matches the data. For our purposes, matching the share of newly unemployed matters more than matching the level of gross flows. Estimating $s_{t}$ and $f_{t}$ at a monthly frequency, which should substantially mitigate the bias from within-period flows, makes little difference for our results.

${ }^{11}$ We do not have information on monetary eligibility at cyclical frequencies. We conjecture that monetary eligibility is procyclical, as newly unemployed transition from weaker labor markets during recessions. In that case, ignoring monetary eligibility leads us to understate the volatility of the take-up rate and ultimately of $z$. Prior to 1968 , we impute the share of newly unemployed that satisfy nonmonetary eligibility using the fitted values from a regression of the share on leads and lags of the unemployment rate and of the fraction of job losers among all durations of unemployed.
} 
further details). Evaluating equation (6) using the time series of $u_{t}, s_{t}, f_{t}$, $\omega_{t}^{e}$, and $\omega_{t}^{u}$ gives our time series of eligibility $\omega_{t}$. The take-up rate equals $\zeta_{t}=\phi_{t} / \omega_{t}$.

\section{Taxes}

Our next step is to construct time series for the three tax rates, $\tau_{t}^{w}, \tau_{t}^{B}$, and $\tau_{t}^{C}$. We measure the tax rates $\tau_{t}^{w}$ and $\tau_{t}^{B}$ as the population average of effective tax rates on labor compensation and UI benefits, respectively. For tax unit $i$, let income $y_{i, t}=y_{s, i, t}+y_{n, i, t}+y_{B, i, t}+y_{o, i, t}$ be the sum of taxable income from wages and salaries $y_{s, i, t}$, nontaxable labor compensation (such as health insurance) $y_{n, i, t}$, income from UI $y_{B, i, t}$, and other income (such as capital income) $y_{o, i, t}$ Let TL $\left(y_{i, t}\right)$ be the total tax liability in period $t$ of household $i$ with income $y_{i, t}$. We measure the effective marginal tax rate on income source $k \in\{s, B\}$ as

$$
\tau_{i, t}^{k}=\frac{\operatorname{TL}\left(y_{i, t}-y_{n, i, t}\right)-\operatorname{TL}\left(y_{i, t}-y_{n, i, t}-y_{k, i, t}\right)}{y_{k, i, t}} .
$$

In equation (18), $\tau_{i, t}^{k}$ captures the effective tax rate faced by a household making an extensive margin decision regarding either working or taking up benefits, holding constant other income sources. We implement equation (18) using IRS Public Use Files in conjunction with National Bureau of Economic Research TAXSIM. The files contain a nationally representative sample of approximately 140,000 tax filing units per year in 1960, 1962, 1964, and 1966-2008. Our measure of tax liability TL includes federal income taxes, state income taxes, and Federal Insurance Contributions Act (FICA) taxes. We construct $\tau_{t}^{s}$ and $\tau_{t}^{B}$ as the average in the population of households with positive wage and salary income and positive UI income, respectively. Because taxes apply on a calendar year basis, we set the tax rate in each quarter of a calendar year to the tax rate estimated for the whole calendar year. ${ }^{12}$

To estimate the effective tax rate on total labor income, $\tau_{t}^{w}$, we adjust $\tau_{t}^{s}$ to take into account nontaxable compensation, $\tau_{t}^{w}=\left[y_{s, t} /\left(y_{s, t}+y_{n, t}\right)\right] \tau_{t}^{s}$. In the adjustment factor, taxable labor compensation $y_{s, t}$ is the difference between total labor compensation (NIPA table 2.1, line 2) and the sum of employer-provided health insurance (NIPA table 7.8, line 12) and life insurance (NIPA table 7.8, line 18). Total labor income $y_{s, t}+y_{n, t}$ in the denominator of the adjustment is total labor compensation (NIPA table 2.1, line 2).

\footnotetext{
${ }^{12}$ Following the availability of tax law in TAXSIM, we include state taxes beginning in 1977. We extrapolate both $\tau_{t}^{s}$ and $\tau_{t}^{B}$ for 2009-12 using the fitted values from a regression of the tax rates as computed using the IRS Public Use Files on the tax rates computed using the same methodology but with the March CPS as the microdata.
} 
We use data on net taxes on production and imports (NIPA table 1.12, lines 19 and 20) to measure consumption taxes $\tau_{t}^{C}$. These indirect taxes include items such as federal excise taxes, state sales taxes, and property taxes and therefore affect both consumption and investment spending. We calculate consumption taxes as a fraction of net taxes on production and imports. The fraction equals the ratio of personal consumption expenditures to the sum of personal consumption expenditures and gross private domestic investment from NIPA table 1.1.5. We estimate $\tau_{t}^{C}$ by dividing the fraction of these indirect taxes by the difference between personal consumption expenditure and the fraction of these indirect taxes.

Figure 2 shows our estimated tax series $\tau_{t}^{w}, \tau_{t}^{B}$, and $\tau_{t}^{C}$. The series exhibit sharp movements around legislated tax changes. For example, UI benefits become partially federally taxable in 1979 and fully taxable as part of the Tax Reform Act of 1986. The sharp drop in $\tau_{t}^{B}$ in 2009 reflects the exemption of the first $\$ 2,400$ of UI income from federal adjusted gross income in that year. The secular increase in $\tau_{t}^{w}$ until $2000 \mathrm{re}-$ flects mostly the increase in FICA tax rates. Both $\tau_{t}^{w}$ and $\tau_{t}^{B}$ decline as a result of the Bush tax cuts in the early 2000s. ${ }^{13}$

\section{Benefit Take-Up Cost Function}

Our final input into equation (11) is the elasticity of the cost of take-up $\psi\left(\zeta_{t}\right)$ with respect to the take-up rate $\zeta_{t}$, which we denote by $\alpha=$ $\psi^{\prime}\left(\zeta_{t}\right) \zeta_{t} / \psi\left(\zeta_{t}\right)$. We estimate $\alpha$ using the first-order condition for the take-up rate $(9)$. Using a circumflex to denote percentage deviations of variables from their trends, the first-order condition yields

$$
\widehat{\zeta}_{t}=\left(\frac{1}{\alpha-1}\right)\left[\widehat{\lambda}_{t}+\left(\widehat{1-\tau_{t}^{B}}\right)-\left(\widehat{1+\tau_{t}^{C}}\right)+\widehat{\tilde{B}}_{t}\right]
$$

We have described the measurement of all variables that enter equation (19) with the exception of the marginal utility of consumption $\hat{\lambda}_{t}$. The marginal utility depends on the underlying utility function. In this section we show results under the case of separable preferences between $\log$ consumption and the disutility of nonworking time. In this case we obtain $\hat{\lambda}_{t}=-\hat{C}_{t}$, where $C_{t}$ denotes NIPA consumption of nondurable and nonhousing services per person 16 years or older.

Under this measure of the marginal utility we estimate a value of $\alpha=$ 1.87 with a standard error of 0.15 . The take-up rate in the data comoves positively with the utility value of after-tax benefits per recipient, gener-

${ }^{13}$ Our series for $\tau_{t}^{w}$ correlates highly with an effective labor income tax rate series calculated from NIPA sources. After extending the methodology of Mendoza, Razin, and Tesar (1994) to our longer sample, the $R^{2}$ from a regression of the one series on the other exceeds 85 percent. 


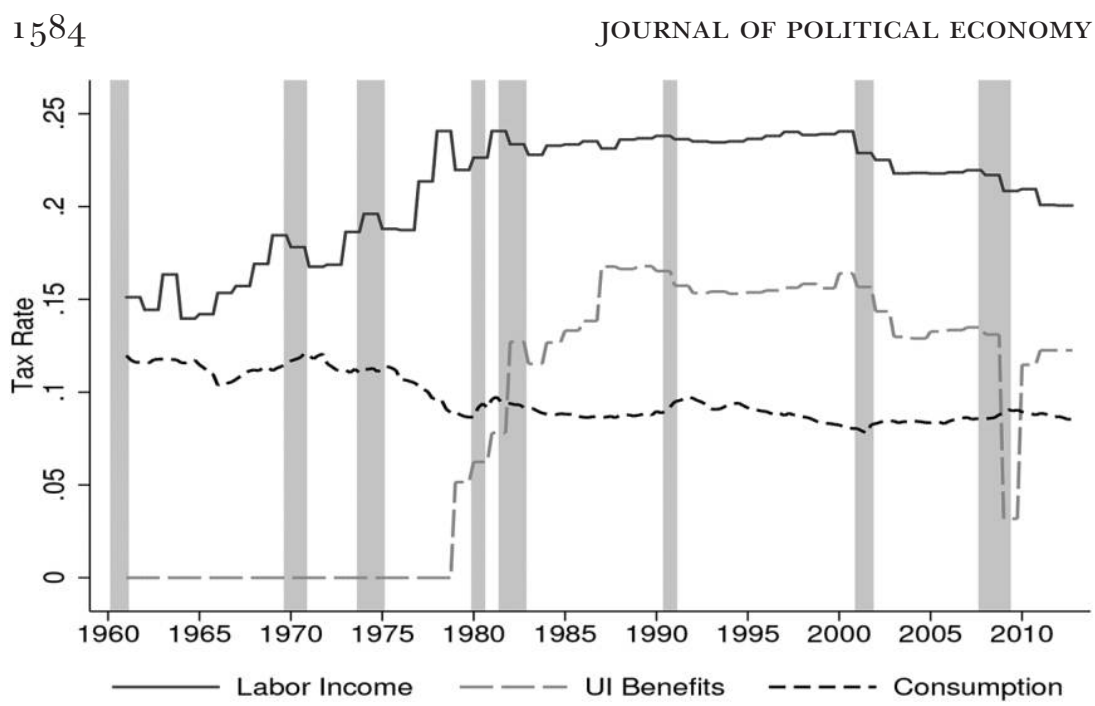

FIG. 2.- Tax rates. The figure reports the average effective tax rate on labor earnings, UI benefits, and consumption. For labor earnings and UI benefits, the underlying data come from the IRS Public Use Files in conjunction with NBER TAXSIM, and equation (18) provides the formula for the effective tax rate. The consumption rate is based on NIPA data. Color version available as an online enhancement.

ating an estimate of $\alpha>1$. In Section IV we present three additional preference specifications together with the separable case. While each of the four specifications implies a different $\hat{\lambda}_{t}$ series, the estimates of $\alpha$ are stable across the different preference specifications.

\section{E. Results}

We now combine our measurements of the various components to calculate a time series of $b$ using equation (11). ${ }^{14}$ We normalize $b$ and other variables by expressing them relative to the mean level of the after-tax marginal product of employment $p^{\tau}$. Denoting total output by $Y_{t}$ and the pretax marginal product of employment by $p_{t}=\partial Y_{t} / \partial e_{t}$, we define the after-tax marginal product of employment as $p_{t}^{\tau}=p_{t}\left(1-\tau_{t}^{w}\right) /(1+$

${ }^{14}$ To make this equation operational in the data, we drop the expectations operator and substitute

$$
\frac{\beta \lambda_{t+1}\left(1+\tau_{t}^{C}\right)}{\lambda_{t}\left(1+\tau_{t+1}^{C}\right)}=\frac{1}{1+r_{t+1}} .
$$

We measure $r_{t+1}$ using the interest rate on 10-year US Treasuries less a measure of expected inflation. 
$\tau_{t}^{C}$ ), where $\tau_{t}^{w}$ is the labor income tax rate and $\tau_{t}^{C}$ is the tax rate on consumption. We normalize its mean value to $p^{\tau}=1 .{ }^{15}$

In figure 3 we present the time series of $b$ relative to the mean after-tax marginal product of employment $p^{\tau}=1$. Our estimated $b$ is countercyclical and very volatile, mostly reflecting the significant increase in UI eligibility and take-up during recessions. The correlation between the cyclical component of $b$ and the cyclical component of real GDP per capita is -.45 . The standard deviation of the cyclical component of $b$ is roughly six times larger than the standard deviation of the cyclical component of real GDP per capita.

A key finding that emerges from our analysis is that the mean level of $b$ is small. We find that the mean $b$ in our sample is roughly 6 percent of the after-tax marginal product of employment $p^{\tau}$. This estimated level of $b$ is much smaller than the values typically used in calibrated versions of the Mortensen-Pissarides model. ${ }^{16}$

What explains our estimate? Beginning with the UI component of $b$, the sample mean of pretax benefits per recipient, $\tilde{B}$, is 21.5 percent of the pretax marginal product $p$ and 30 percent of the after-tax marginal product $p^{\tau} \cdot{ }^{17}$ However, on average, only about $\phi=\omega \zeta=40$ percent of unemployed actually receive benefits. Therefore, pretax benefits per unemployed $B_{u}=\phi \tilde{B}$ equal 12 percent of the after-tax marginal product. After-tax benefits per unemployed, $\left(1-\tau^{B}\right) B_{u} /\left(1+\tau^{C}\right)$, equal roughly 10 percent of the after-tax marginal product. The expiration of benefits reduces the value of UI benefits to 8 percent of the after-tax marginal product, and take-up disutility costs further reduce the value of UI benefits to 4 percent of the after-tax marginal product. Finally, adding the $B_{n}$

${ }^{15}$ Let $Y_{t}=F_{t}\left(K_{t}, e_{t} N_{t}\right)$ be a constant returns to scale aggregate production function. We set to $\nu=0.333$ the elasticity of output with respect to capital. We measure the pretax marginal product of employment, $p_{t}$, as $1-\nu$ multiplied by real GDP and then divided by the number of employed. The marginal product of total labor hours is given by $x_{t}=\partial Y_{t} / \partial\left(e_{t} N_{t}\right)=$ $p_{t} / N_{t}$. We use a superscript $\tau$ to also denote the after-tax marginal product of total labor $x_{t}^{\tau}=x_{t}\left(1-\tau_{t}^{w}\right) /\left(1+\tau_{t}^{C}\right)$. We normalize mean hours per worker to $N=1$ and therefore $x^{\tau}=1$.

${ }_{16}$ The sensitivity of reported reservation wages to UI benefits suggests one respect in which our $b$ may still be too large. In our model, the increase in the reservation wage for individuals already receiving UI is given by the tax-adjusted term in braces in eq. (11), which has a sample average value of roughly 0.69 . Estimates of the increase in reservation wages when UI benefits increase range from zero (Krueger and Mueller 2013) to as large as 0.42 (Feldstein and Poterba 1984).

${ }^{17}$ A rate of 21.5 percent accords well with the benefit levels used by Mortensen and Nagypal (2007) and Hall and Milgrom (2008) and the rate suggested by Hornstein et al. (2005). The Department of Labor estimates a wage replacement rate of about 45 percent (http://workforcesecurity.doleta.gov/unemploy/ui_replacement_rates.asp). Converting a wage replacement rate of 45 percent to a total compensation replacement rate requires multiplying by the ratio of wages to total compensation, or a factor of about 0.8 . The remaining difference can be explained by the gap between compensation and the marginal product and from differences in productivity and compensation between those receiving UI and the economywide average. We address the issue of heterogeneity in Sec. VI. 


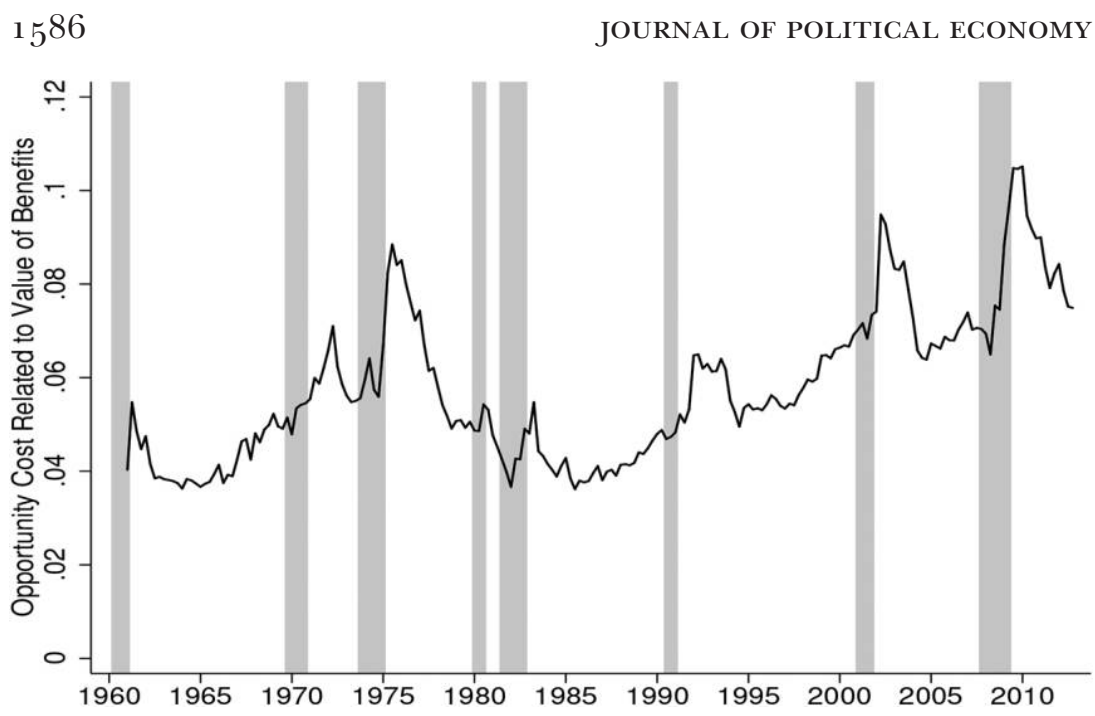

FIG. 3.- Time series of the $b$ component of opportunity cost. The figure reports the time series of the benefits component of the opportunity cost $b$.

component yields $b=0.06$. To summarize our calculations for the mean level of $b$, we show in equation (20) how each term contributes to our estimate:

$b=\underbrace{B_{n}}_{0.02}+\underbrace{B_{u}}_{0.12} \underbrace{\left(\frac{1-\tau^{B}}{1+\tau^{C}}\right)}_{0.83} \underbrace{\left(1-\frac{1}{\alpha}\right)}_{0.47} \underbrace{[\text { braces in eq. (11)] }}_{0.83}=0.06$.

\section{Measurement of the $\xi$ Component}

We now turn to the value of nonworking time relative to consumption $\xi$. To measure $\xi$ we use equation (12) and proceed in three steps. First, we specify utility functions. Second, we measure in the data the consumption of the employed and unemployed and hours per worker. Third, we use our estimates of consumptions and hours to calibrate preference parameters and time endowments, which are used as inputs into the measurement of $\xi$.

\section{A. Preferences and Time Endowments}

Flow utility is a function of a bundle of consumption and working time, $U^{s}\left(C^{s}, N^{s}\right)$, for each employment status $s \in\{e, u\}$. We let $N_{t}^{e}=N_{t}$ denote hours worked by the employed and $N_{t}^{u}=0$ denote hours worked by the unemployed. Denote by $L^{u}$ the (constant) endowment of time that un- 
employed spend on leisure and home production activities. Denote by $T$ any fixed time cost associated with working. Time spent on leisure and home production by the employed is therefore given by $L_{t}^{e}=L^{u}-T-$ $N_{t}^{e}$.

We measure the $\xi$ component of the opportunity cost for each of three widely used utility functions:

SEP:

$$
U_{t}^{s}=\log \left(C_{t}^{s}\right)-\frac{\chi \epsilon}{1+\epsilon}\left(N_{t}^{s}+T\right)^{1+(1 / \epsilon)}
$$

CFE:

$$
U_{t}^{s}=\frac{1}{1-\rho}\left\{\left(C_{t}^{s}\right)^{1-\rho}\left[1-(1-\rho) \frac{\chi \epsilon}{1+\epsilon}\left(N_{t}^{s}+T\right)^{1+(1 / \epsilon)}\right]^{\rho}-1\right\} ;
$$

CD:

$$
U_{t}^{s}=\frac{1-\chi}{1-\rho}\left(C_{t}^{s}\right)^{1-\rho}\left(L_{t}^{s}\right)^{\chi(1-\rho) /(1-\chi)} .
$$

The first two utility functions feature a constant Frisch elasticity of labor supply along the intensive margin, $\epsilon$, in the absence of fixed time costs $T=0$. The utility function in equation (21), denoted by SEP, is separable between consumption and hours. The preferences defined in equation (22), labeled CFE, allow for nonseparability between consumption and hours worked. ${ }^{18} \mathrm{CFE}$ preferences nest SEP preferences when $\rho=1$. With $\rho>1$, consumption and nonworking time are substitutes and the consumption of the employed exceeds the consumption of the unemployed. The Cobb-Douglas (CD) utility function in equation (23) explicitly introduces leisure and home production time in the utility function of the unemployed. CD preferences feature a nonseparability between consumption and nonworking time, but they do not admit a constant Frisch elasticity even when $T=0$.

\section{B. Consumption}

For nonseparable preferences, the measurement of $\xi$ requires time series of consumptions of the employed $C_{t}^{e}$ and the unemployed $C_{t}^{u}$. Let $s \in\{e, u, n, r)$ denote persons 16 years or older who are employed, unemployed, out of the labor force but of working age (16-64), and older than 65 years old, respectively. Let $\pi_{t}^{s}$ be the fraction of the population belonging in each group. Time series of $\pi_{t}^{s}$ come directly from published tabulations by the BLS.

${ }^{18}$ See Shimer (2010) and Trabandt and Uhlig (2011) for further discussion of these preferences. 
Denote by $C_{t}^{s}$ consumption expenditure on nondurable goods and nonhousing services per member of group $s$. We have the adding-up identity

$$
\pi_{t}^{e} C_{t}^{e}+\pi_{t}^{u} C_{t}^{u}+\pi_{t}^{n} C_{t}^{n}+\pi_{t}^{r} C_{t}^{r}=C_{t}^{\mathrm{NPA}},
$$

where $C_{t}^{\mathrm{NIPA}}$ is NIPA consumption of nondurable goods and nonhousing services per person 16 years or older. Defining $\gamma_{t}^{s}=C_{t}^{s} / C_{t}^{e}$ as the ratio of consumption in status $s$ to consumption when employed, we solve equation (24) for the consumption of an employed:

$$
C_{t}^{e}=\frac{C_{t}^{\mathrm{NIPA}}}{\sum_{s} \pi_{t}^{s} \gamma_{t}^{s}}
$$

Equation (25) together with estimates of the consumption ratios $\gamma_{t}^{s}$ provide the basis for deriving the time series of consumptions for the employed and unemployed and for calibrating the utility functions in Section IV.D.

We now turn to our estimates of the consumption ratios $\gamma_{t}^{s}$. Let $C_{i, k, t}^{s}$ denote the instantaneous expenditure on consumption category $k$ of an individual $i$ in group $s$ at time $t$. When employed, individual $i$ has expenditure $C_{i, k, t}^{e}=\exp \left\{\phi_{k, t} \mathbf{X}_{i, t}+\epsilon_{k, i, t}\right\} \tilde{C}_{k, t}$, where $\mathbf{X}_{i, t}$ denotes a vector of demographic characteristics, $\phi_{k, t}$ a vector of parameters, $\epsilon_{k, i, t}$ a mean zero idiosyncratic component uncorrelated with employment status, and $\tilde{C}_{k, t}$ a base level of consumption. For every $s \in\{e, u, n, r\}$, we use the definition of $\gamma_{k, t}^{s}$ and obtain

$$
C_{k, i, t}^{s}=\gamma_{k, t}^{s} \exp \left\{\phi_{k, l} \mathbf{X}_{i, t}+\epsilon_{k, i, t}\right\} \tilde{C}_{k, t} .
$$

For a working-age individual with potential status $e, u$, or $n$, we integrate over the reporting period and take logs to obtain

$$
\ln C_{k, i, t}=\gamma_{k, t}^{0}+\phi_{k, t} \mathbf{X}_{i, t}+\left(\tilde{\gamma}_{k, t}^{u}-1\right) D_{i, t}^{u}+\left(\tilde{\gamma}_{k, t}^{n}-1\right) D_{i, t}^{n}+\epsilon_{k, i, t},
$$

where $\gamma_{k, t}^{0}=\ln \tilde{C}_{k, t}$ and the variables $D_{i, t}^{u}$ and $D_{i, t}^{n}$ measure the fraction of time an individual spends as unemployed and out of the labor force, respectively. ${ }^{19}$ In equation (27), $\tilde{\gamma}_{k, t}^{s}-1$ denotes the difference between

${ }^{19}$ In deriving our estimating equation we replace the term $\ln \left[1-\Sigma_{s}\left(1-\gamma_{k, t}^{s}\right) D_{i, t}^{s}\right]$ with $\sum_{s} D_{i, t}^{s}\left(\tilde{\gamma}_{k, t}^{s}-1\right)$, where the coefficients $\tilde{\gamma}_{k, t}^{s}$ are related to the coefficients $\gamma_{k, t}^{s}$ and to terms of order higher than one in the linear approximation of the left-hand side around $\gamma_{k, t}^{s}=1$ for all $s$. Derivations for the estimating equation for $\gamma_{t}^{r}$ proceed analogously. The derivation of eq. (27) assumes that $\tilde{\gamma}_{k, t}^{u}$ does not vary with unemployment duration $D_{i, t}^{u}$. In unreported regressions, we have estimated $\tilde{\gamma}_{k, t}^{u}$ nonparametrically by grouping households into bins of weeks unemployed. Our estimated $\tilde{\gamma}_{k, t}^{u}$ for each bin indicates a duration-independent $\tilde{\gamma}_{k, t}^{u}$. This finding supports the assumption in the model that the instantaneous consumption of the unemployed does not depend on duration. 
the $\log$ consumption of an individual in group $s$ and the log consumption of an employed. Therefore, to recover the actual consumption ratios $\gamma_{k, t}^{s}$ from the log point differences, we use the formula $\gamma_{k, t}^{s}=\exp \left(\tilde{\gamma}_{k, t}^{s}-1\right)$.

We begin by estimating equation (27) using the Consumer Expenditure Survey. The CE asks respondents for the number of weeks worked over the previous year but does not ask questions about search activity while not working. We set $D_{i, t}^{n}=1$ if the respondent reports 0 weeks worked over the previous year and does not give "unable to find job" as the reason for not working. For the rest of the respondents, we define $D_{i, t}^{u}=1-(\text { weeks worked })_{i, t} / 52$. We average $D_{i, t}^{u}$ and $D_{i, t}^{n}$ at the household level. To minimize inclusion of households with adults transitioning out of the labor force within the reporting year, we restrict the sample to households with a head aged 30-55 at the time of the final interview. We include a rich set of controls in $\mathbf{X}_{i, t}$ to control for taste shocks and ex ante permanent income that potentially could correlate with an individual's employment status. ${ }^{20}$

We focus our discussion of results on the unemployment margin because $\gamma^{u}$ will directly inform our calibration of preferences. Figure 4 reports $\gamma^{u}$ by year, for the aggregate category of nondurable goods and services, less housing, health, and education. The mean of $\gamma^{u}$ implies a 21 percent decline in expenditure on nondurable goods and services during unemployment. The series does not exhibit any apparent cyclicality, with a correlation between the cyclical components of $\gamma^{u}$ and the unemployment rate of -.03 . We also test for cyclicality parametrically by interacting $D_{i, t}^{u}$ in equation (27) with both the state and national unemployment rates and again cannot reject the hypothesis that the consumption ratio is acyclical (see table 2).

The cross-sectional identification in equation (27) relies on the richness of the control variables to absorb differences in ex ante permanent income. We complement this approach with panel regressions relying on within-household changes in consumption. First-differencing equation (27) to remove the individual fixed effect, we obtain ${ }^{21}$

\footnotetext{
${ }^{20}$ These controls include the mean age of the household head and spouse; the mean age squared; the marital status; an indicator variable for Caucasian or not; indicator variables for four categories of education of the household head (less than high school, high school diploma, some college, college degree) interacted with year; indicator variables for owning a house without a mortgage, owning a house with a mortgage, or renting a house, interacted with year; indicator variables for quantiles of the value of the home conditional on owning, by region and year, interacted with year; a binary variable for having positive financial assets; family size; and family size squared.

${ }^{21}$ In deriving eq. (28), we impose that $\phi_{k, t}=\phi_{k}$. In unreported results, we have also estimated eq. (28) by interacting a set of controls with year categorical variables and find that the PSID results in table 2 remain essentially unchanged.
} 


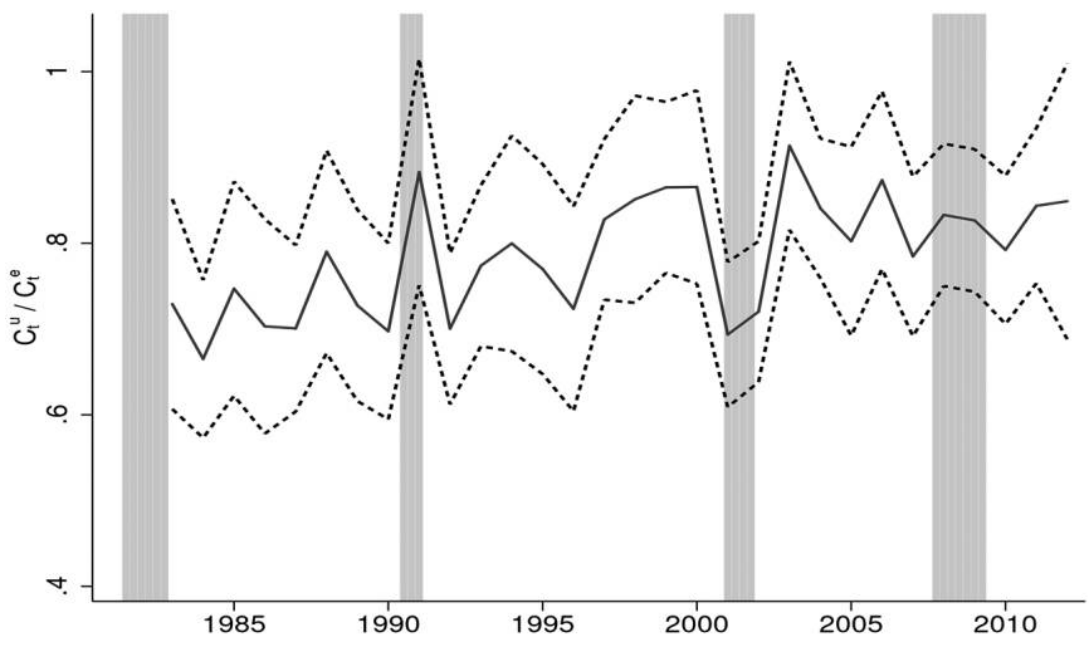

FIG. 4.-Decline in nondurables and services upon unemployment. The solid line reports the estimates of $\gamma_{t}^{u}=\exp \left(\tilde{\gamma}_{u, t}-1\right)$, where $\tilde{\gamma}_{u, t}$ is estimated from equation (27) using data from the CE. The dotted lines give 95 percent confidence interval bands based on robust standard errors. Regressions are weighted using survey sampling weights. See footnote 20 for included covariates. Color version available as an online enhancement.

$$
\begin{aligned}
\Delta \ln C_{k, i, t}= & \Delta \gamma_{k, t}^{0}+\sum_{s \in\{u, n\}}\left[\left(\tilde{\gamma}_{k, t}^{s}-1\right) \Delta D_{i, t}^{s}+\Delta \tilde{\gamma}_{k, t}^{s} D_{i, t-1}^{s}\right] \\
& +\Delta \epsilon_{i, k, t} .
\end{aligned}
$$

We use the panel dimension of the PSID to estimate equation (28)..$^{22}$ Table 2 reports estimates of $\tilde{\gamma}_{k}^{u}$ from equation (27) for the CE and from equation (28) for the PSID. For total food, the PSID suggests a somewhat larger $\tilde{\gamma}_{k}^{u}$ than the CE, but this may reflect an upward bias in the PSID. ${ }^{23}$ We also exploit the new questions in the PSID covering broader mea-

${ }^{22}$ The PSID asks detailed questions about labor force status. We use these to construct the fraction of the reporting period in unemployment in a manner analogous to the BLS U-3 definition,

$$
D_{i, t}^{u}=\left(\frac{\text { weeks searching or on temporary layoff in year } t}{\text { weeks in the labor force in year } t}\right)_{i} .
$$

This more precise definition of unemployment constitutes an additional dimension along which the PSID provides robustness for the CE results.

${ }^{23}$ The PSID asks about "usual" weekly expenditure on food at home and then about food away from home without prompting a frequency. These questions leave some ambiguity as to whether the food expenditure questions apply to the time of the interview or to the previous year. We follow the recent literature in mapping the questions to the previous year's expenditure (Blundell, Pistaferri, and Preston 2008). However, if some respondents interpret the question as referencing food expenditure at the time of the interview, the resulting measurement error in unemployment status would bias upward the estimated $\tilde{\gamma}_{k}$ in the PSID regressions. Additionally, while the CE asks about detailed categories every 3 months, the PSID asks about the broad categories of food at home and food away and over a longer 
TABLE 2

Relative Expenditure of The Unemployed $\tilde{\gamma}^{u}$

\begin{tabular}{|c|c|c|c|c|c|}
\hline & \multicolumn{2}{|c|}{ TOTAL FoOD } & \multicolumn{2}{|c|}{$\begin{array}{c}\text { Food, Clothing, } \\
\text { Recreation, VACATion }\end{array}$} & \multirow{2}{*}{$\begin{array}{c}\text { Nondurables } \\
\text { AND SERVICES } \\
\text { CE }\end{array}$} \\
\hline & $\mathrm{CE}$ & PSID & CE & PSID & \\
\hline$\tilde{\gamma}^{u}$ & $\begin{array}{l}.79 \\
(.013)\end{array}$ & $\begin{array}{c}.86 \\
(.045)\end{array}$ & $\begin{array}{c}.72 \\
(.015)\end{array}$ & $\begin{array}{c}.73 \\
(.096)\end{array}$ & $\begin{array}{l}.77 \\
(.012)\end{array}$ \\
\hline$p$-value $\left(\tilde{\gamma}^{u} \perp U^{\text {state }}, U^{\text {national }}\right)$ & .86 & .43 & .87 & .24 & .66 \\
\hline Observations & 53,413 & 31,616 & 53,413 & 4,871 & 53,413 \\
\hline
\end{tabular}

Note.-The parameter $\tilde{\gamma}^{u}$ gives the $\log$ point difference between the expenditure of an unemployed and the expenditure of an employed. The CE columns cover reporting years 1983-2012. The category nondurables and services in the last column excludes expenditures on housing, health care, and education. The PSID columns cover reporting years 1983-86, 1989-96, 1998, 2000, 2002, 2004, 2006, 2008, and 2010 for food and years 2004, 2006, 2008, and 2010 for clothing, recreation, and vacations. Equation (27) is used for the CE and eq. (28) is used for the PSID. Regressions are weighted using sampling weights. Standard errors are in parentheses and are based on heteroskedastic robust (CE) or heteroskedastic robust and clustered by household head (PSID) variance matrix. $p$-value $\left(\tilde{\gamma}^{u} \perp U^{\text {state }}, U^{\text {national }}\right)$ reports the $p$-value of a joint test that interacting $D_{i, t}^{u}$ with the state and national unemployment rates in eq. (27) or (28) yields coefficients equal to zero.

sures of consumption expenditure. Here the estimated $\tilde{\gamma}_{k}^{u}$ from the PSID appears nearly indistinguishable from the $\tilde{\gamma}_{k}^{u}$ from the CE for the same set of categories. The overall similarity between the CE and the PSID results suggests that the control variables in $\mathbf{X}_{i, t}$ proxy well for differences in ex ante permanent income. Because of nonhomotheticities across consumption categories, our preferred results come from the CE for total nondurable goods and services less housing, health, and education, reported in the last column of the table.

Our estimate of the consumption drop upon unemployment lies comfortably within the range of those found in previous studies. In an early assessment, Burgess et al. (1981) report in a survey of UI recipients after 5 weeks of unemployment that expenditure on the categories of food, clothing, entertainment, and travel fell by 25.7 percent relative to before the unemployment spell. Gruber (1997) reports a decline in food expenditure of 6.8 percent in the PSID for the period up to 1987. The difference between his results and ours mostly stems from the removal of households with a threefold change in consumption from his sample. Using a survey of Canadians unemployed for 6 months that asks about total expenditure over the previous month as well as expenditure in

recall period. Hence even if respondents interpret the question as referring to the previous year, recall bias may cause their response to partly reflect their current consumption patterns. The newer PSID expenditure questions on clothing, recreation, and vacation explicitly reference the previous year as the reporting period. The smaller difference between CE and PSID for these categories is consistent with reference period ambiguity introducing a bias into the PSID food results. 
the month before unemployment, Browning and Crossley (2001) find a mean decline of 14 percent. Aguiar and Hurst (2005) report a 19 percent decline in food expenditure among the unemployed using scanner data. Stephens (2004) conducts an analysis of the effects of job loss on consumption in the Health and Retirement Survey (HRS) and the PSID and finds a decline in food expenditure between 12 (PSID) and 15 (HRS) percent when an individual experiences a job loss between interviews. Finally, using cross-sectional variation in the PSID, Saporta-Eksten (2014) estimates an 8 percent decline in consumption expenditure on selected categories in the year in which a job loss occurs. However, Saporta-Eksten does not condition on the fraction of the year spent out of work. To convert the 8 percent estimate into an instantaneous consumption decline requires adjusting by the fraction of the year spent jobless. Assuming an average unemployment duration of 17 weeks would imply a consumption decline of roughly 24 percent, in line with our estimate. A similar type of adjustment applies to the Stephens (2004) estimate.

We apply our estimates of the consumption ratios in two steps. First, the calibration of preference parameters in Section IV.D requires data on the mean level of $C_{t}^{e}$ (denoted by $C^{e}$ ) and the mean level of $C_{t}^{u}$ (denoted by $C^{u}$ ). For these means, we impose constancy of the consumption ratios $\gamma_{t}^{s}=\gamma^{s}$ in equation (25) and obtain a time series for $C_{t}^{e}$ and $C_{t}^{u}=$ $\gamma^{u} C_{t}^{e} \cdot{ }^{24}$ We then define $C^{e}=(1 / T) \Sigma_{t} C_{t}^{e}$ and $C^{u}=(1 / T) \Sigma_{t} C_{t}^{u}$. Second, obtaining a time series of $\xi_{t}$ requires a time series of $C_{t}^{e}$ and $C_{t}^{u}$. We jointly impose the adding-up constraint for total consumption in equation (24) and the risk-sharing condition in equation (7) to solve for the time series of $C_{t}^{e}$ and $C_{t}^{u}$. This approach ensures the internal consistency of our estimated parameters with the model's analogue of the first-order condition for risk sharing in the data. The time-varying consumption ratio $C_{t}^{u} / C_{t}^{e}$ implied by this procedure is extremely smooth, falling comfortably in the confidence interval of the estimated $\gamma_{t}^{u}{ }^{25}$

\section{Hours per Worker}

The next input for the measurement of $\xi$ is hours per worker $N_{t}$. We measure $N_{t}$ as the average weekly hours reported in the basic monthly CPS microdata by the employed. These data start in 1968 . We extend the se-

\footnotetext{
${ }^{24}$ We set $\gamma^{u}=0.793$, the value from estimating eq. (27) for a constant $\gamma^{u}$. For the other categories, we estimate $\gamma^{n}=0.743$ and $\gamma^{r}=0.940$. Similarly to our estimates of $\gamma^{u}$, we cannot reject acyclicality of these consumption ratios. We also use the same time-invariant $\gamma^{n}=$ 0.743 and $\gamma^{r}=0.940$ when estimating the time series of $C_{t}^{e}$ and $C_{t}^{u}$.

${ }_{25}$ The model-generated consumption ratio is mildly countercyclical because hours per worker are procyclical and consumption and nonworking time are substitutes in the utility functions we consider. Alternatively, imposing constancy of the ratio $C_{t}^{u} / C_{t}^{e}=\gamma^{u}=0.793$ and using this constant ratio and eq. (24) to solve for the time paths of $C_{t}^{e}$ and $C_{t}^{u}$ does not change our results.
} 


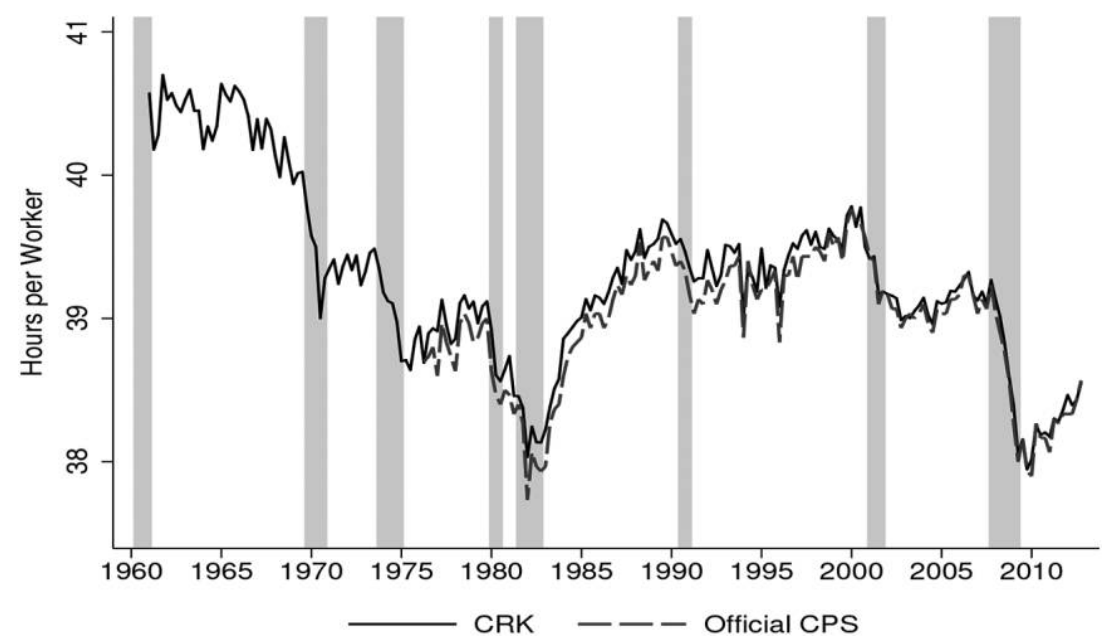

FIG. 5.- Hours per worker. The figure plots seasonally adjusted hours per worker. The line CRK shows our own estimate using the CPS basic monthly files and a seasonal adjustment algorithm. The official CPS line shows BLS series LNS12005054. Color version available as an online enhancement.

ries back to 1961 and fill in some missing months between 1968 and 1975 using data from Cociuba, Prescott, and Ueberfeldt (2012). We seasonally adjust the series by first estimating an autoregressive moving average model including categorical variables for each month of the year and months in which each of Good Friday, Easter Monday, Labor Day, Columbus Day, or Veterans Day occurred during the CPS reference week. Then we apply a multistep moving average filter similar to that contained in X-11. Appendix B.1 provides further details on the seasonal adjustment.

Figure 5 shows the resulting hours series (CRK). Hours per worker are procyclical. The figure also shows the official BLS series from the CPS for comparison. During the overlapping period 1976-2012, the cyclical component of our CRK series displays a correlation of .96 with the "official CPS" series. ${ }^{26}$

\section{Parameterization}

We now use our estimates of consumptions and hours to calibrate four models. The first model features SEP preferences and has no fixed time

${ }^{26}$ The official CPS series used in fig. 5 is the BLS seasonally adjusted hours per worker series LNS12005054. The BLS also offers a seasonally unadjusted series of hours per worker for nonagricultural industries that starts in 1948 (LNU02033120). After applying our seasonal adjustment to this alternative series, we find a correlation of .98 between the cyclical component of our CRK series and the cyclical component of this alternative series. We prefer using the CRK series as a baseline for comparability with our later analyses that require measurement of hours per worker by educational group. 
costs $(T=0)$. The second model features CFE preferences and also has $T=0$. The third model features CD preferences, a definition of nonworking time of unemployed $L^{u}$ that excludes some time uses, and $T=$ 0 . The fourth model also features CD preferences but adopts the most extreme view of what could be considered utility-enhancing leisure of unemployed $L^{u}$ and allows for fixed time costs $T>0$. The purpose of the fourth model is to try to rationalize the level of the opportunity cost $z=0.955$ advocated by Hagedorn and Manovskii (2008).

In general, our calibration strategy involves choosing two parameters to make two first-order conditions hold exactly at the mean values of the variables in the sample. The first condition is the risk-sharing condition (7) requiring the equalization of the marginal utility of consumption between the employed and unemployed. For this condition, we use the mean values of consumptions estimated in Section IV.B, $C^{e}=0.681$ and $C^{u}=$ 0.540 . The second condition is an efficiency condition for the choice of hours per worker, evaluated at mean sample values:

$$
-\frac{\partial U\left(C^{e}, N\right)}{\partial N}=\lambda\left(\frac{1-\tau^{w}}{1+\tau^{C}}\right) x,
$$

where $x$ denotes the marginal product of total labor hours. In equation (29) we use the mean sample values of $\tau^{C}=0.096$ and $\tau^{w}=0.209$, and we have normalized $N=1 .^{27}$

Panel A of table 3 presents our parameterization. For the SEP preferences, the risk-sharing condition always implies $C_{t}^{e}=C_{t}^{u}=C_{t}$. Thus, with perfect risk sharing, these preferences cannot match the consumption decline at unemployment. We follow Pistaferri (2003) and Hall (2009) and set the Frisch elasticity of labor supply to $\epsilon=0.7$. We then choose $\chi=1.48$ to make equation (29) hold exactly at the mean values of the variables in the sample. Panel B shows the elasticities implied by our parameterization. The intertemporal elasticity of substitution in consumption is $-1 / \epsilon_{\lambda C}=1$ and the Frisch elasticity of labor supply is $\epsilon_{N w}=\epsilon=0.7$. The elasticity of hours with respect to the marginal utility (holding the wage constant) is $\epsilon_{N \lambda}=0.7$. Finally, the elasticity of hours with respect to consumption is also $-\epsilon_{N C}=-\epsilon_{N \lambda} \epsilon_{\lambda C}=0.7$. The latter two elasticities measure wealth effects on hours along the intensive margin. ${ }^{28}$

\footnotetext{
${ }^{27}$ Our measurement of $\xi$ does not require eq. (29) to hold in any particular period. We require eq. (29) only in the steady state of the model in order to calibrate preference parameters. This equation arises as a first-order condition, e.g., under Nash bargaining. We view such an equilibrium as a desirable outcome in the long run, as any other equilibrium would imply that firms and workers coordinate at an inefficient allocation. See Shimer $(2010,53, \mathrm{fn} .6)$ for a similar argument in a model without taxes.

${ }^{28}$ The mapping of the elasticities $\epsilon_{\Lambda \lambda}$ and $\epsilon_{N C}$ into the elasticity of hours with respect to income $\epsilon_{N Y}$ (which has a more direct mapping to empirical studies) requires specifying the income process and structure of the capital markets. For example, if shocks are relatively transitory and workers can access capital markets to smooth such shocks, then consump-
} 
TABLE 3

Parameterization of Preferences

\begin{tabular}{|c|c|c|c|c|c|c|c|c|c|c|c|}
\hline \multirow[b]{2}{*}{ Preferences } & \multicolumn{7}{|c|}{ PARAmeters } & \multicolumn{4}{|c|}{ ELASTICITIES } \\
\hline & $L^{u}$ & $T$ & $\epsilon$ & $\chi$ & $\rho$ & $\alpha$ & $\operatorname{SE}(\alpha)$ & $-1 / \epsilon_{\lambda C}$ & $\epsilon_{N w}$ & $\epsilon_{\Lambda \lambda}$ & $-\epsilon_{N C}$ \\
\hline SEP & & .00 & .70 & 1.48 & & 1.87 & .15 & 1.00 & .70 & .70 & .70 \\
\hline CFE & & .00 & .70 & 1.22 & 1.52 & 1.86 & .14 & .66 & .70 & .46 & .70 \\
\hline CD1 & 2.64 & .00 & & .71 & 1.25 & 1.86 & .15 & .80 & 1.10 & 3.07 & 3.85 \\
\hline CD2 & 4.33 & .19 & & .82 & 1.19 & 1.86 & .15 & .84 & 1.82 & 6.43 & 7.63 \\
\hline
\end{tabular}

Note.-Each row of the table reports the calibrated level of time endowment $L^{u}$, fixed costs of working $T$, the preference parameters $\epsilon, \chi$, and $\rho$, the estimate of the UI take-up elasticity $\alpha$, and various reduced-form elasticities for the indicated preference specification.

For the CFE preferences we again set $\epsilon=\epsilon_{N w}=0.7$. The solution of equations (7) and (29) gives values of $\chi=1.22$ and $\rho=1.52$. The intertemporal elasticity of substitution in consumption is $-1 / \epsilon_{\lambda C}=1 / \rho=$ 0.66 . The elasticity of hours with respect to the marginal utility of wealth is $\epsilon_{N \lambda}=\epsilon / \rho=0.46$ and with respect to consumption is $\epsilon_{N C}=0.70 .{ }^{29}$

For CD preferences, we additionally need an estimate of the time endowment of the unemployed $L^{u}$. Using the American Time Use Survey (2003-12), we find that unemployed spend 47.6 hours per week on leisure activities (e.g., watching television, listening to music, and socializing with friends), 16.5 hours per week on discretionary sleeping time (defined as the excess sleeping time over 49 hours), 24.6 hours per week on home production (e.g., cooking, home ownership activities, and shopping), 6.9 hours per week on child care, and 7 hours per week on activities such as education, religious activities, and own medical care. Dividing the sum of these hours (102.6) by hours per worker (38.8), we obtain $L^{u}=2.64$ relative to a mean value of $N=1$.

In table 3 , the row labeled CD1 presents our parameterization when $L^{u}=2.64$ and there are no fixed time costs associated with working $(T=0)$. The row labeled CD2 presents an alternative parameterization of CD preferences that yields the level of $z=0.955$ advocated by Hagedorn and Manovskii (2008). This parameterization sets $L^{u}=4.33$, corresponding to the broadest view that all 168 hours per week potentially constitute utility-enhancing nonworking time. It also requires fixed time costs of working equal to 19 percent of average hours per worker. ${ }^{30}$ As

tion and $\lambda$ will not change much in response to income shocks, making $\epsilon_{N Y}$ small. The opposite holds if shocks are permanent or borrowing possibilities are restricted.

${ }_{29}$ These values are close to the values used in Hall (2009), with the small difference mostly reflecting that our estimated $\rho$ is lower than the $\rho$ implicit in Hall's formulation. See Hall's appendix for a summary of evidence on these elasticities. In general, the CFE calibration comes closer to matching the evidence cited in Hall than the SEP, CD1, and CD2 calibrations.

so A value of $T=0.19$, implying fixed costs of more than 7 hours per week, appears quite large relative to typical estimates of commuting time. Rogerson and Wallenius (2013) re- 
table 3 shows, both sets of CD preferences feature a higher Frisch elasticity of labor supply than the SEP and CFE calibrations. The CD preferences also imply much stronger wealth effects on hours than SEP and CFE preferences.

Table 3 also presents estimates of the elasticity of the cost function with respect to take-up, $\alpha$, from an OLS regression of equation (19), along with Newey-West standard errors with four lags. The four preference specifications imply different $\hat{\lambda}_{t}$ series. However, the estimates of $\alpha$ are stable across the different preference specifications.

\section{E. Results}

Combining our estimates of consumption by labor force status and hours per worker with our calibrated utility functions, we now estimate a time series of $\xi$ according to equation (12). For each of the four calibrated models, we first discuss the estimated levels of $\xi$. Then we discuss the cyclicality of $\xi$.

We obtain the following levels of $\xi$ (relative to an after-tax marginal product of employment $\left.p^{\tau}=1\right)$ :

$$
\xi^{\mathrm{SEP}}=0.41, \quad \xi^{\mathrm{CFE}}=0.41, \quad \xi^{\mathrm{CD} 1}=0.70, \quad \xi^{\mathrm{CD} 2}=0.90 .
$$

We begin our analysis by considering the steady-state value of $\xi$ under the SEP and CFE specifications: ${ }^{31}$

$$
\xi^{\mathrm{SEP}}=\xi^{\mathrm{CFE}}=\left(\frac{\epsilon}{1+\epsilon}\right) p^{\tau}
$$

For a value of $\epsilon=0.7$, we obtain $\xi^{\mathrm{SEP}}=\xi^{\mathrm{CFE}}=0.41$ relative to the aftertax marginal product of $p^{\tau}=1$. A higher Frisch elasticity of labor supply results in a higher level of opportunity cost. However, using these utility specifications, one would need to assume a Frisch elasticity of 9 to rationalize a level of $\xi$ equal to 0.90 . Could, alternatively, fixed time costs explain such a high level of $\xi$ under SEP or CFE preferences? Introducing fixed time costs changes the level to $\xi^{\mathrm{SEP}}=\xi^{\mathrm{CFE}}=p^{\tau}(1+T / N) \epsilon /(1+\epsilon)$. It also changes the Frisch elasticity to $(1+T / N) \epsilon$. For $T$ roughly equal

view evidence on commuting time and find that $T$ is approximately 0.1 . Rogerson and Wallenius also point out that commuting time does not constitute a fixed cost if individuals adjust the number of days at work rather than hours per day, making $T=0.1$ an upper bound under this interpretation of the fixed cost. In our robustness checks we consider an alternative model in which fixed costs are denominated directly in terms of utility rather than time.

${ }^{31}$ The appendix to Hall (2014) first derives this equation for SEP preferences. The equation results from substituting the condition for hours in eq. (29) into the expression for $\xi$ in eq. (12). Because our measurement exercise does not require that eq. (29) holds in any particular period, eq. (31) need not hold period by period. 
to 120 percent of $N$, one would estimate $\xi=0.90$ with a less extreme Frisch elasticity of 1.54. However, the magnitude of these fixed costs is implausible.

In the absence of fixed time costs $(T=0)$, we can write $\xi$ under CD preferences as a function of the endowment of nonworking time of the unemployed $L^{u}$ :

$$
\xi^{\mathrm{CD}}=\left[\frac{1-\gamma^{u}}{-\log \left(\gamma^{u}\right)}\right]\left(L^{u}-1\right) \log \left(\frac{L^{u}}{L^{u}-1}\right) p^{\tau},
$$

where $\gamma^{u}=0.793$ is the consumption of the unemployed relative to the employed. We obtain that $\lim _{L^{u} \rightarrow 1} \xi^{\mathrm{CD}}=0$,

$$
\lim _{L^{u} \rightarrow \infty} \xi^{\mathrm{CD}}=\left[\frac{1-\gamma^{u}}{-\log \left(\gamma^{u}\right)}\right] p^{\tau}=0.89
$$

and that between these limiting cases $\xi^{\mathrm{CD}}$ is an increasing function of the endowment of time $L^{u}$. Our estimate of $L^{u}=2.64$ under calibration CD1 yields $\xi^{\mathrm{CD}}=0.70$. Model CD2 implies a higher value of $\xi$ both because we calibrate the endowment of time at the higher level of $L^{u}=4.33$ and because we introduce fixed time costs associated with working $T=0.19$. Without fixed time costs but with $L^{u}=4.33$, we would have estimated $\xi=0.78$. Therefore, of the 20 percentage point difference in $\xi$ between calibration CD2 and calibration CD1, 12 percentage points are due to fixed costs and 8 percentage points are due to the higher level of the time endowment. ${ }^{32}$

To summarize, our estimated levels of $\xi$ differ substantially across specifications. We show how the level of $\xi$ depends on the underlying utility function, the estimated time endowment of the unemployed, and fixed costs associated with working. ${ }^{33}$ Despite these meaningful differences, we now show that the cyclicality of $\xi$ is quite stable across different specifications.

\footnotetext{
${ }^{32}$ Using a narrower definition of leisure and home production that roughly corresponds to the time uses defined in Aguiar, Hurst, and Karabarbounis (2013), we obtain $L^{u}=2.00$ and $\xi=0.62$. Our inference about the cyclicality of $z$ in this case is not very different than in the CD1 and CD2 cases. For example, we obtain an elasticity $\epsilon(\hat{z}, \hat{p})=0.87$ as opposed to values of 0.85 and 0.83 under CD1 and CD2, respectively.

${ }^{33}$ If flow utilities were equalized, $U^{u}=U^{e}$, then we would have obtained $\xi=C^{e}-C^{u}$. In this case, our estimates of consumption differences imply that $\xi=0.14$. A higher level of $\xi$ requires $\left(U^{u}-U^{e}\right) / \lambda>0$. The interpretation of $\left(U^{u}-U^{e}\right) / \lambda>0$ is that nonworking time is valued at a sufficiently high level relative to consumption, which is a standard assumption in the literature (see Rogerson and Wright 1988). In the model with incomplete markets discussed in app. C, the unemployed's expected sum of discounted utility flows $V^{u}$ is lower than the employed's expected sum of discounted utility flows $V^{e}$, even when flow utilities satisfy $U^{u}>U^{e}$.
} 


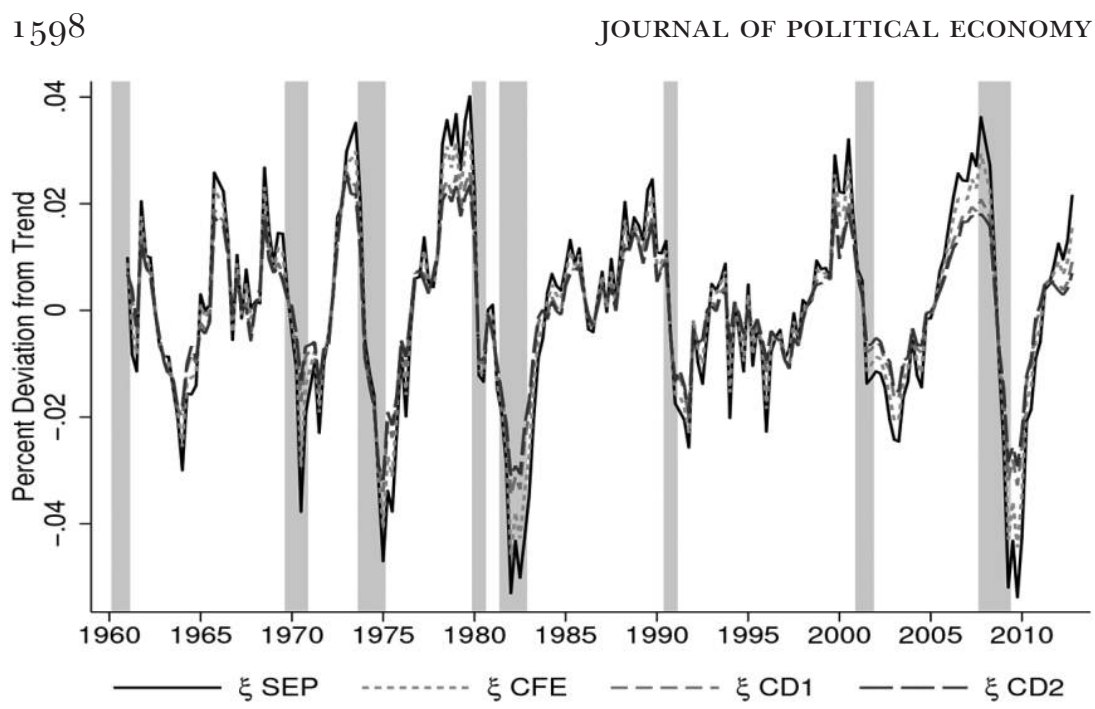

FIG. 6.-Cyclical components of $\xi$. Variables are logged and HP filtered with a smoothing parameter of 1,600. Color version available as an online enhancement.

Figure 6 shows the percentage deviation of $\xi$ from its trend. We compute trends of variables using the Hodrick-Prescott (HP) filter with a smoothing parameter of 1,600 . We see that all four specifications result in highly similar cyclical components of $\xi$. In particular, all four specifications imply a procyclical and volatile $\xi$.

To develop intuition about the cyclicality of $\xi$, it is useful to consider the SEP utility function. Under SEP we obtain

$$
\xi_{t}^{\mathrm{SEP}}=\left(\frac{\chi \epsilon}{1+\epsilon}\right) N_{t}^{1+(1 / \epsilon)} C_{t} .
$$

The $\xi$ component of the opportunity cost is procyclical because in the data both hours per worker and consumption are procyclical. ${ }^{34}$ The intuition for the cyclicality of $\xi$ in the SEP case carries over to the other preference specifications. In all cases, procyclical hours and consumption imply a procyclical $\xi$ component of the opportunity cost. Quantitatively, $\xi$ is less volatile in the nonseparable specifications because, with procyclical hours, the complementarity in preferences between consumption and hours ameliorates the cyclicality of the marginal utility of consumption $\lambda$.

\footnotetext{
${ }^{34}$ Our preferred measure of consumption $C_{t}^{\mathrm{NIPA}}$ in this paper excludes durables and housing services. At a quarterly frequency and using an HP filter with a smoothing parameter of 1,600 to detrend variables, the volatility of the cyclical component of $C_{t}^{\mathrm{NIPA}}$ relative to the volatility of the cyclical component of real GDP per person 16 years or older is 0.66 . However, the stock of durables is also volatile over the business cycle. The relative volatility of the cyclical component of the real stock of durables is 0.73 .
} 


\section{The Opportunity Cost of Employment in the Data}

We now combine our measurements of the two components, $b$ and $\xi$, and describe the properties of the opportunity cost of employment $z=b+\xi$.

\section{A. Baseline Results}

Table 4 presents summary statistics for the period 1961(1)-2012(4) for each set of preferences. The level of $z$ ranges between 0.47 and 0.96 of the after-tax marginal product of employment $p^{\tau}$. The variation in the average level of $z$ across preferences reflects the variation in the average level of the component of the opportunity cost associated with the value of nonworking time $\xi$. In all cases, $\xi$ constitutes the largest part of $z$, ranging between 0.41 and 0.90 .

Turning to the cyclicality of the opportunity cost, figure 7 plots the percentage deviation of $z$ from its trend for each of the four parameterizations. The four series track each other closely. All appear to be procyclical, falling during each recession in our sample. Table 4 confirms that $z$ comoves positively with real GDP per capita $Y$ over the business cycle. It also shows that $z$ is quite volatile over the business cycle, with the

TABLE 4

Summary Statistics, $1961(1)-2012(4)$

\begin{tabular}{lrrrr}
\hline \hline Statistic & SEP & CFE & CD1 & CD2 \\
\hline$p^{\tau}$ & 1.00 & 1.00 & 1.00 & 1.00 \\
$p$ & 1.39 & 1.39 & 1.39 & 1.39 \\
$z$ & .47 & .47 & .75 & .96 \\
$\xi$ & .41 & .41 & .70 & .90 \\
$b$ & .06 & .06 & .06 & .06 \\
$\mathrm{SD}(\hat{Y})$ & 1.50 & 1.50 & 1.50 & 1.50 \\
$\mathrm{SD}(\hat{p})$ & .89 & .89 & .89 & .89 \\
$\mathrm{SD}(\hat{z})$ & 1.66 & 1.52 & 1.19 & 1.10 \\
$\mathrm{SD}(\hat{\xi})$ & 1.92 & 1.63 & 1.29 & 1.20 \\
$\mathrm{SD}(\hat{b})$ & 8.97 & 8.95 & 8.96 & 8.96 \\
$\operatorname{corr}(\hat{z}, \hat{Y})$ & .52 & .42 & .55 & .61 \\
$\operatorname{corr}(\hat{\xi}, \hat{Y})$ & .87 & .87 & .86 & .86 \\
$\operatorname{corr}(\hat{b}, \hat{Y})$ & -.45 & -.45 & -.45 & -.45 \\
$\epsilon(\hat{z}, \hat{p})$ & 1.11 & .92 & .85 & .83 \\
$\operatorname{Confidence~interval~}$ & {$[.74,1.49]$} & {$[.56,1.28]$} & {$[.59,1.11]$} & {$[.60,1.06]$} \\
\hline
\end{tabular}

NoTE.-The table reports summary statistics of the after-tax marginal product of employment $p^{\tau}$, the pretax marginal product of employment $p$, the opportunity $\cos t z$, the two components of the opportunity cost $\xi$ and $b$, and output per working-age person $Y$. We normalize the level of all variables relative to the sample mean of $p^{\tau}$. We denote the percentage deviation of some variable $x_{t}$ from its trend by $\hat{x}_{t}$. We compute trends of variables using the HP filter with a smoothing parameter of 1,600 . The elasticity $\epsilon\left(\hat{x}_{1}, \hat{x}_{2}\right)$ is the regression coefficient of $\hat{x}_{1}$ on $\hat{x}_{2}$. The 95 percent confidence intervals based on Newey-West standard errors with four lags are in brackets. 


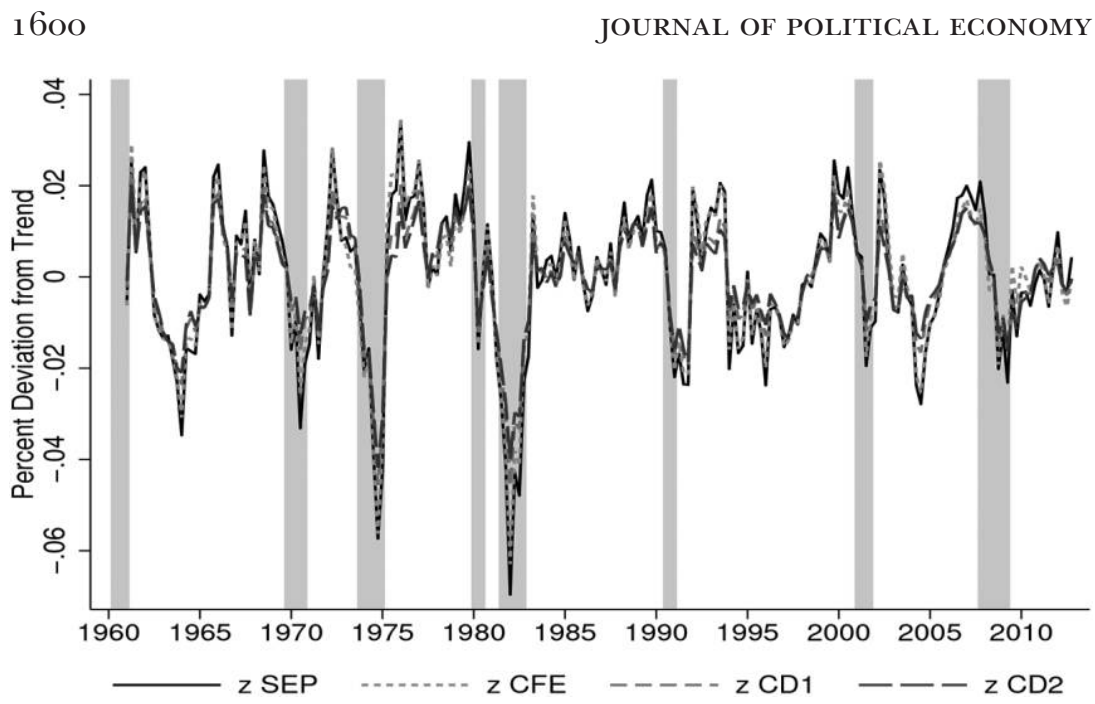

FIG. 7.-Cyclicality of the opportunity cost of employment. Variables are logged and HP filtered with a smoothing parameter of 1,600. Color version available as an online enhancement.

standard deviation of its cyclical component exceeding the standard deviation of the cyclical component of the marginal product $p$.

The procyclical movement of $z$ reflects the dominance of the $\xi$ component in the sum $z=b+\xi$. As discussed before and summarized in table 4 , the $b$ component is countercyclical and very volatile. However, the small level of $b$ makes its fluctuations relatively unimportant for $z$.

Table 4 also reports the elasticity of $\hat{z}$ with respect to $\hat{p}$ as a metric that takes into account both the correlation between the two variables and the relative volatilities. As we show below, this elasticity is an informative statistic for the magnitude of unemployment fluctuations in a wide class of models. For consistency with prior literature that focuses on total factor productivity (TFP) shocks as the driving force in business cycle models and to correct for measurement error in $\hat{p}$, we instrument $\hat{p}$ with the cyclical component of the Fernald (2012) unadjusted TFP series. ${ }^{35}$ The resulting elasticities of $\hat{z}$ with respect to $\hat{p}$ range between 0.83 and 1.11 . The elasticity declines when moving from SEP to other preferences, reflecting the nonseparability embedded in the other specifications. We cannot reject the null hypothesis that the elasticity equals one for any of the preference specifications. We conclude that the opportunity cost of

${ }^{35}$ We motivate our focus on $p$ instead of $p^{\tau}$ by appealing to prior literature in which productivity shocks are treated as exogenous. Empirically, the elasticity of the cyclical component of the tax wedge $\left(1-\tau^{w}\right) /\left(1+\tau^{C}\right)$ with respect to the cyclical component of $p$ in our data is 0.014 (instrumented) and 0.067 (not instrumented). That is, taxes respond very little to cyclical movements in $p$. 
employment moves roughly proportionally with the marginal product of employment over the business cycle.

\section{B. Sensitivity Analysis}

We assess the sensitivity of the cyclicality of $z$ to a number of modeling assumptions and use of data moments. In table 5, each row reports the elasticity $\epsilon(\hat{z}, \hat{p})$ under a different alternative scenario for each of the four preference specifications indicated in the column headings. The first row provides the baseline elasticities. Unless otherwise noted, in each sensitivity exercise we recalibrate all model parameters whenever necessary in order to achieve the same targets as in our baseline procedure.

Rows 1-4 provide further intuition for the cyclicality of $z$ by selectively shutting off the cyclicality of various inputs. Row 1 reports elasticities $\epsilon(\hat{z}, \hat{p})$ in the counterfactual in which the $b$ component of $z$ always equals its trend. The estimated elasticities increase, reflecting the fact that $b$ is countercyclical. However, these increases are relatively small because $b$ constitutes a small part of the opportunity cost. To assess the contribution of the $\xi$ component for $z$ fluctuations, in row 2 we set the $\xi$ component equal to its trend. We find that the elasticities $\epsilon(\hat{z}, \hat{p})$ become slightly negative or zero. None of the four estimated elasticities is statistically significant at the 10 percent level. Setting $\xi$ equal to its trend implies an acyclical $z$ because the level of $b$ is much smaller than the level of $\xi$.

Row 3 reports elasticities $\epsilon(\hat{z}, \hat{p})$ when our underlying measure of consumption $C_{t}^{\mathrm{NIPA}}$ equals its trend. In this counterfactual scenario, all of the

TABLE 5

Sensitivity of Elasticity $\epsilon(\hat{z}, \hat{p})$

\begin{tabular}{lrrrr}
\hline \hline Case & SEP & CFE & CD1 & CD2 \\
\hline Baseline results & 1.11 & .92 & .85 & .83 \\
1. Benefit component $b_{t}$ equal to trend & 1.32 & 1.13 & .98 & .93 \\
2. Nonworking time component $\xi_{t}$ equal to trend & -.06 & -.09 & -.02 & .00 \\
3. Consumption $C_{t}^{\mathrm{NIPA}}$ equal to trend & .52 & .33 & .22 & .19 \\
4. Hours $N_{t}$ equal to trend & .54 & .46 & .57 & .60 \\
5. Smaller consumption decline $\left(\gamma^{u}=.9\right)$ & 1.11 & 1.02 & .92 & .90 \\
6. Hours $N_{t}$ of salary workers & 1.03 & .85 & .81 & .80 \\
7. Hours $N_{t}$ of hourly workers & 1.21 & 1.00 & .90 & .87 \\
8. Hours $N_{t}$ adjusted for composition & 1.19 & .98 & .89 & .86 \\
9. Higher Frisch elasticity $(\epsilon=2)$ & 1.01 & .86 & $\mathrm{NA}$ & $\mathrm{NA}$ \\
10. Alternative model of take-up $(\zeta=1.00)$ & 1.01 & .85 & .82 & .82 \\
11. No taxes $\left(\tau^{w}=\tau^{C}=\tau^{B}=0\right)$ & 1.20 & 1.01 & .91 & .87 \\
12. Fixed utility costs of working for $z=.96$ & .96 & .91 & .85 & .84 \\
13. Baxter-King filter & 1.17 & .97 & .91 & .88 \\
14. No instrumenting & 1.01 & .87 & .78 & .75 \\
15. No instrumenting and Baxter-King filter & 1.15 & .98 & .89 & .86 \\
\hline
\end{tabular}

NoTE.-Each row of the table reports the elasticity $\epsilon(\hat{z}, \hat{p})$ after reconstructing the time series for $z$ under the scenario indicated in the left-hand column. 
elasticities decline substantially. We conclude that the procyclicality of consumption is a major factor in generating the procyclical behavior of $z$. In row 4 we set hours per worker $N_{t}$ equal to its trend. The elasticities decrease, but by less than in the scenario in which consumption equals its trend. We conclude that the procyclicality of hours contributes to the procyclicality of $z$ but that, quantitatively, cyclical movements in hours per worker matter less than cyclical movements in consumption.

Rows 5-15 explore robustness to using other plausible data moments or modeling assumptions. Row 5 assesses the sensitivity of the estimated elasticities to the value of the ratio of the consumption of the unemployed relative to the employed. Our baseline calibration of preference parameters uses the value of $\gamma^{u}=0.793$. Row 5 instead sets $\gamma^{u}=0.9$. With procyclical hours, the complementarity between hours and consumption makes the marginal utility $\lambda$ less cyclical, which in turn ameliorates the procyclicality of $\xi$. The complementarity in preferences becomes stronger when the consumption ratio $\gamma^{u}$ is lower. Therefore, increasing $\gamma^{u}$ increases all estimated elasticities for nonseparable preferences. ${ }^{36}$

Rows 6 and 7 replace $N_{t}$ with series for hours per worker constructed separately for salaried and hourly workers, respectively. Hourly workers experience more procyclical hours per worker than salary workers, explaining the larger elasticities in row 7 than in row 6 . However, both types of workers have quite volatile and procyclical hours series, leading to significant procyclicality in $z$ in both cases. ${ }^{37}$

In row 8 we adjust our measure of hours for compositional changes. In principle, hours per worker could decline in recessions because economic activity reallocates toward industries or demographic groups with lower average hours. To adjust for such compositional shifts, we regress hours of employed on industry, gender, education, and age bracket categorical variables. We then construct hours for each worker as the sum of the regression residual and a sample mean, aggregate these hours, and apply our seasonal adjustment procedure. The elasticities $\epsilon(\hat{z}, \hat{p})$ increase slightly as a result of this compositional adjustment. In practice, compositional changes dampen rather than exacerbate cyclical movements in hours per worker.

\footnotetext{
${ }^{36}$ Our baseline SEP preferences imply a unitary elasticity of intertemporal substitution. Using separable but nonbalanced growth preferences of the form $U=\left(C^{1-\rho}-1\right) /(1-$ $\rho)-[\chi \epsilon /(1+\epsilon)] N^{1+1 / \epsilon}$ allows us to decouple $\rho$ from the consumption decline upon unemployment and examine the sensitivity of our results to the assumed elasticity of intertemporal substitution. With $\rho=2$, which implies an intertemporal elasticity of onehalf, we find $\epsilon(\hat{z}, \hat{p})=1.77$. Intuitively, for given cyclical components of consumption, increasing $\rho$ makes $\lambda$ more cyclical.

${ }^{37}$ We construct hours per worker for hourly and salary workers from the CPS monthly files. The identification of the type of worker is possible on a continual basis only starting in 1982. Before then we impute hours for these two groups based on a projection on aggregate hours.
} 
In row 9 we increase the Frisch elasticity of labor supply for SEP and CFE preferences to $\epsilon=2$ and recalibrate the remaining preference parameters to match the same targets as in our baseline results. A larger $\epsilon$ implies a smaller effect from fluctuations of hours per worker on fluctuations of the $\xi$ component of the opportunity cost. However, even for $\epsilon=2$ the estimated elasticities $\epsilon(\hat{z}, \hat{p})$ remain close to one. We view the value of two as an upper bound of reasonable values of the Frisch elasticity, given that our model has an extensive margin of labor supply.

Row 10 examines the sensitivity of our results to the assumed model of UI take-up. Motivated by the evidence in Blank and Card (1991) and Anderson and Meyer (1997) that take-up rates are significantly below one and respond to benefit levels, in our baseline model eligible unemployed take up benefits when the utility value of after-tax UI benefits exceeds the utility cost of take-up. We now consider an alternative model in which the opportunity cost of eligible unemployed always includes the full value of their UI entitlement with no disutility. Thus, in equation (11) we set $\alpha$ to infinity and $\zeta_{t}=1$. With this modification, the level of $b$ increases. However, the estimated elasticities $\epsilon(\hat{z}, \hat{p})$ do not change much because without a take-up margin $b$ fluctuates much less.

In row 11 , we set all taxes to zero and recalibrate all parameters in the model without taxes. For all preference specifications we obtain larger elasticities. Taxes increase the level of $b$ relative to the after-tax marginal product because the tax rate on UI benefits $\tau^{B}$ is lower than the tax rate on labor income $\tau^{w}$. Because the $b$ component is countercyclical, reducing its importance in the model without taxes generates larger elasticities.

In our baseline model, under calibration CD2, we introduced fixed time costs in order to achieve a high level of $z$. We now consider an alternative model in which fixed costs associated with working are denominated directly in terms of utility rather than in units of time. Specifically, each individual incurs a fixed cost (FC) when moving from unemployment to employment that, for simplicity, enters additively into the utility function. With this modification, $\xi_{t}$ is given by equation (12) plus the additive term FC/ $\lambda_{t}$. For each preference specification, we choose FC such that we obtain the mean value of $z=0.955$ suggested by Hagedorn and Manovskii (2008). As row 12 of table 5 shows, the elasticity $\epsilon(\hat{z}, \hat{p})$ declines somewhat relative to our baseline results only for the SEP case.

Finally, rows 13-15 report the sensitivity of our results to our procedure for estimating the elasticities $\epsilon(\hat{z}, \hat{p})$. Row 13 uses the Baxter-King (BK) filter to separate the trend from the cycle, using a bandwidth of 6-32 quarters. All elasticities increase slightly. Row 14 reports elasticities using the HP filter but without instrumenting for the marginal product. Here the elasticities decline by $0.05-0.1$. Finally, row 15 shows that our results remain largely unchanged when we use the BK filter and we do not instrument for the marginal product. 
To summarize, the combination of procyclical hours per worker, procyclical consumption, and a small level of benefits $b$ implies a procyclical and volatile opportunity cost $z$. Further, we estimate that a 1 percent increase in $p$ is associated with an increase in $z$ of at least 0.8 percent, and we cannot reject the hypothesis that $z$ and $p$ move proportionally over the business cycle. This result appears robust to various preference specifications, alternative data definitions, and modeling choices.

\section{Heterogeneity across Skills}

Our measurement of $z$ for the average unemployed followed from the assumption that all unemployed search for the same jobs and employers cannot discriminate ex ante in choosing a potential worker with whom to bargain. We now relax this assumption and allow workers to differ along observable characteristics that may be correlated with their opportunity costs.

The economy consists of $J$ heterogeneous households. In our empirical implementation we separate workers into four educational attainment categories. Each household $j$ contains fraction $l_{j}$ of the population. Within each group $j$, a fraction $e_{j t}$ are employed and a fraction $u_{j t}$ are unemployed. There are $J$ segmented labor markets. We denote by $f_{j t}$ the job-finding rate in market $j$ and by $s_{j t}$ the separation rate. Employment for group $j$ evolves as $e_{j t+1}=\left(1-s_{j t}\right) e_{j t}+f_{j t} u_{j t}$.

The problem of each household $j$ is

$$
\begin{aligned}
W_{j}^{h}= & \max \mathbb{E}_{0} \sum_{t=0}^{\infty} \beta^{t}\left[l_{j} e_{j t} U_{j}\left(C_{j t}^{e}, N_{j t}\right)+l_{j}\left(1-e_{j t}\right) U_{j}\left(C_{j t}^{u}, 0\right)\right. \\
& \left.-l_{j}\left(1-e_{j t}\right) \omega_{j t} \psi\left(\zeta_{j t}\right)\right],
\end{aligned}
$$

subject to the budget constraint,

$$
\begin{gathered}
\left(1+\tau_{t}^{C}\right)\left[l_{j} e_{j t} C_{j t}^{e}+l_{j}\left(1-e_{j t}\right) C_{j t}^{u}\right]+I_{j t}+\Pi_{j t} \\
=\left(1-\tau_{j t}^{w}\right) w_{j t} l_{j} e_{j t} N_{j t}+l_{j}\left(1-e_{j t}\right) B_{j t}+\left(r_{t}+\delta\right) K_{j t},
\end{gathered}
$$

and the law of motion for eligibility,

$$
\omega_{j t+1}=\left[\omega_{j t+1}^{u}\left(1-f_{j t}\right) \frac{u_{j t}}{u_{j t+1}}\right] \omega_{j t}+\omega_{j t+1}^{e} s_{j t} \frac{e_{j t}}{u_{j t+1}} .
$$

We note that flow utilities $U_{j}$ are allowed to vary by $j$. In the budget constraint, after-tax benefits per unemployed of type $j$ are given by $B_{j t}=$ $\left(1+\tau_{t}^{C}\right) B_{n, j t}+\left(1-\tau_{t j}^{B}\right) B_{u, j t}$, where $B_{n, j t}$ denotes non-UI benefits per unemployed, $B_{u, j t}$ denotes UI benefits per unemployed, and $\tau_{t j}^{B}$ denotes the UI tax rate in group $j$. 
To derive the opportunity cost of employment by group $j$, we proceed analogously to the aggregate case analyzed in Section II. We first derive the marginal value of employment for household $j, J_{j t}^{h}=\partial W_{j t}^{h} / \partial\left(l_{j} e_{j t}\right)$, as the sum of a flow payoff (after-tax wages minus opportunity cost) and a continuation value. Then we define the opportunity cost of employment similarly to the aggregate case:

$$
z_{j t}=b_{j t}+\left(C_{j t}^{e}-C_{j t}^{u}\right)-\frac{U_{j t}^{e}-U_{j t}^{u}}{\lambda_{j t}}=b_{j t}+\xi_{j t},
$$

where $b_{j t}$ is given by equation (11) taking into account $j$-specific values of variables. The thrust of our procedure for constructing $z_{j t}$ follows that for the aggregate described in Section III. Here we sketch briefly our estimation and refer the reader to appendix B.2 for more details.

For our estimates of the benefits per unemployed $B_{n, j t}$ and $B_{u, j t}$, we use the March CPS to measure the fraction of survey dollars in each program accruing to the unemployed of category $j$ and the CPS basic monthly files to measure the fraction of unemployed belonging in group $j$. The first two rows of table 6 report the sample averages of $B_{n, j}$ and $B_{u, j}$, expressed relative to a mean aggregate after-tax aggregate marginal product of employment of $p^{\tau}=1$. The opportunity cost of low-skilled workers contains higher non-UI benefits than that of high-skilled workers. This difference reflects the existence of asset and income tests for non-UI benefits, which disqualify many high-skilled workers. By contrast, UI benefits per unemployed increase monotonically with skill level. The average benefit more than doubles for workers with a high school diploma relative to those without. The statutory linking of UI benefits to previous wages explains the positive relationship between skill level and UI benefits per unemployed.

For our estimates of consumptions of employed $C_{j t}^{e}$ and unemployed $C_{j t}^{u}$, we use the CE to measure the consumption declines upon unemployment by group $\gamma_{j}^{u}$ and the relative consumptions of employed of different skills $\gamma_{j i}^{e}=C_{j}^{e} / C_{i}^{e}$. Applying these consumption ratios to an appropriately modified version of the adding-up identity (24), we obtain times series for consumptions. Table 6 shows that the consumption declines upon unemployment $\gamma_{j}^{u}$ are quite stable across different skill groups. It also shows large differences across groups in the consumption of the employed, with consumption increasing monotonically with skill.

We measure hours per worker $N_{j t}$, the separation rate $s_{j t}$, the job-finding rate $f_{j t}$, and taxes $\tau_{j t}^{w}$ and $\tau_{j t}^{B}$ in a way analogous to the aggregate. ${ }^{38}$ Hours

\footnotetext{
${ }^{38}$ For $\tau_{j t}^{w}$ and $\tau_{j t}^{B}$, we apply the procedure described in Sec. III.C to microdata from the March CPS and then benchmark the resulting estimates such that the mean tax rate equals the rate using the IRS Public Use Files.
} 
TABLE 6

Heterogeneity Statistics: 1969(1)-2012(4)

\begin{tabular}{|c|c|c|c|c|}
\hline Statistic & $\begin{array}{l}\text { Less than } \\
\text { High School }\end{array}$ & High School & Some College & $\begin{array}{l}\text { College } \\
\text { or More }\end{array}$ \\
\hline$B_{n, j}$ & .03 & .02 & .01 & .01 \\
\hline$B_{u, j}$ & .06 & .14 & .15 & .18 \\
\hline$\gamma_{j}^{u}$ & .77 & .80 & .79 & .80 \\
\hline$C_{j}^{e}$ & .55 & .63 & .71 & .85 \\
\hline$N_{j}$ & .90 & 1.01 & .99 & 1.07 \\
\hline$s_{j}$ & .10 & .05 & .04 & .02 \\
\hline$f_{j}$ & .70 & .66 & .69 & .64 \\
\hline$\tau_{j}^{w}$ & .18 & .21 & .22 & .25 \\
\hline$\tau_{j}^{B}$ & .07 & .10 & .10 & .14 \\
\hline$p_{j}^{\tau}$ & .69 & .92 & 1.03 & 1.49 \\
\hline \multicolumn{5}{|l|}{ SEP: } \\
\hline$z_{j} / p_{j}^{\tau}$ & .49 & .49 & .47 & .45 \\
\hline$\xi_{j} / p_{j}^{\tau}$ & .42 & .41 & .41 & .41 \\
\hline$b_{j} / p_{j}^{\tau}$ & .07 & .07 & .06 & .04 \\
\hline$\epsilon\left(\hat{z}_{j}, \hat{p}\right)$ & 1.71 & 1.31 & .97 & .67 \\
\hline \multicolumn{5}{|l|}{ CFE: } \\
\hline$z_{j} / p_{j}^{\tau}$ & .49 & .49 & .47 & .45 \\
\hline$\xi_{j} / p_{j}^{\tau}$ & .42 & .41 & .41 & .41 \\
\hline$b_{j} / p_{j}^{\tau}$ & .07 & .07 & .06 & .04 \\
\hline$\epsilon\left(\hat{z}_{j}, \hat{p}\right)$ & 1.43 & 1.08 & .76 & .54 \\
\hline \multicolumn{5}{|l|}{ CD1: } \\
\hline$z_{j} / p_{j}^{\tau}$ & .79 & .78 & .75 & .72 \\
\hline$\xi_{j} / p_{j}^{\tau}$ & .72 & .70 & .70 & .68 \\
\hline$b_{i} / p_{j}^{T}$ & .07 & .07 & .06 & .04 \\
\hline$\epsilon\left(\hat{z}_{j}, \hat{p}\right)$ & 1.19 & .98 & .77 & .64 \\
\hline \multicolumn{5}{|l|}{ CD2: } \\
\hline$z_{j} / p_{j}^{\tau}$ & .96 & .95 & .92 & .89 \\
\hline$\xi_{j} / p_{j}^{\tau}$ & .89 & .87 & .86 & .85 \\
\hline$b_{j} / p_{j}^{T}$ & .07 & .07 & .06 & .04 \\
\hline$\epsilon\left(\hat{z}_{j}, \hat{p}\right)$ & 1.13 & .95 & .78 & .67 \\
\hline
\end{tabular}

Note.-The terms $B_{n, j}, B_{u, j}, C_{j}^{e}$, and $p_{j}^{\tau}$ are expressed as a fraction of the mean aggregate marginal product of employment in the sample. The term $N_{j}$ is expressed as a fraction of the mean aggregate hours per worker in the sample.

per worker $N_{j t}$ are the lowest for workers without a high school diploma and the highest for college-educated workers. The job-finding rate $f_{j t}$ appears relatively stable across groups, whereas the separation rate $s_{j t}$ declines sharply with skill level. Reflecting the progressivity of the income tax system, taxes on both labor and UI income increase monotonically with skill. Table 6 also reports the mean after-tax marginal product of each group $p_{j}^{\tau}=p_{j}\left(1-\tau_{j}^{w}\right) /\left(1+\tau^{C}\right)$, where $p_{j}$ denotes the pretax marginal product. We construct $p_{j t}$ using a constant elasticity of substitution aggregator of the $J$ different labor inputs and calibrate parameters such that, in the steady state of our model, the ratio of marginal products across groups equals the ratio of labor earnings. Given estimates of $C_{j t}^{e}, C_{j t}^{u}, N_{j t}$, and $p_{j t}^{\tau}$, we proceed as in Section IV.A and calibrate group-specific prefer- 


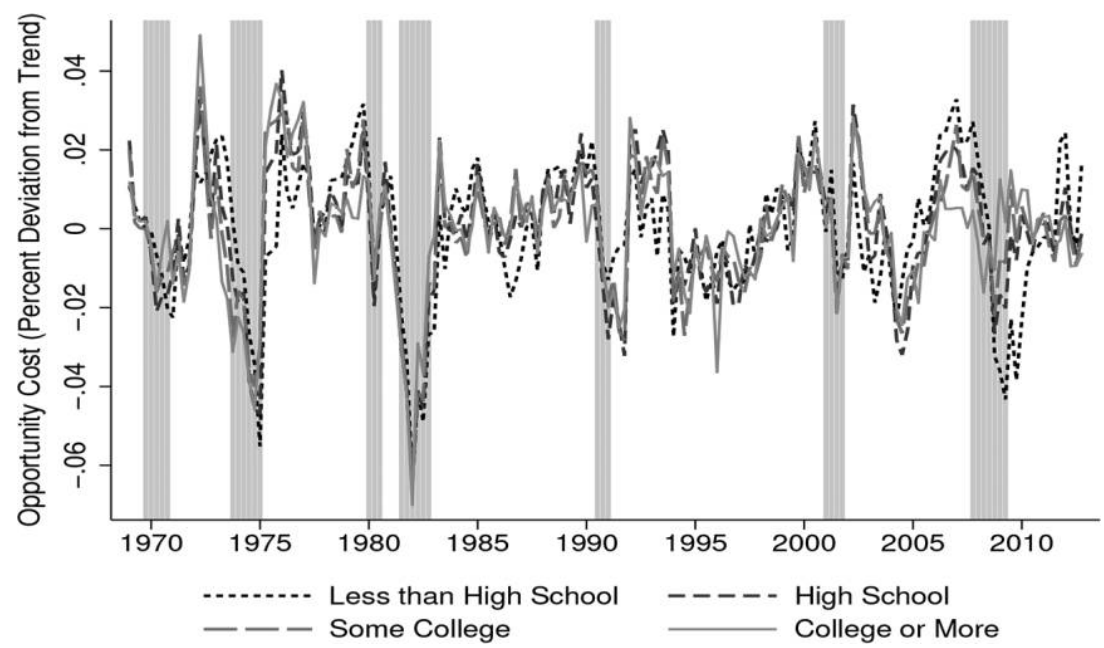

FIG. 8.-Opportunity costs across skills (CFE preferences). Variables are logged and HP filtered with a smoothing parameter of 1,600. Color version available as an online enhancement.

ence parameters using the risk-sharing condition (7) and the efficiency condition for hours (29) for each group $j$.

Figure 8 plots the cyclical components of $z_{j}$ for the CFE preferences. The $z_{j}$ 's are highly synchronized across groups. Table 6 reports various statistics across groups for the SEP, CFE, CD1, and CD2 calibrations. ${ }^{39}$ The level of $z_{j}$ relative to $p_{j}^{\tau}$ is relatively stable across groups. Table 6 also reports the elasticities $\epsilon\left(\hat{z}_{j}, \hat{p}\right)$ by group and utility function. All elasticities appear well above zero, but low-skilled groups exhibit much larger cyclicality than high-skilled groups. The difference partly reflects the larger share of procyclical non-UI benefits in the $b_{j}$ of the low skilled. It also reflects the lower procyclicality of hours per worker $N_{j t}$ for the high skilled.

To summarize, the procyclicality of the opportunity cost is present in each group after we disaggregate individuals by educational attainment. While there are interesting differences across groups, the same economic forces that drive the aggregate $z$ to fluctuate over the business cycle also influence the skill-specific $z_{j}$ 's.

\section{Implications for Unemployment Fluctuations}

In this section we discuss the importance of $z$ for unemployment fluctuations. Section VII.A demonstrates the implications of the cyclicality of $z$

${ }^{39}$ In the CD2 specification we set the fixed time cost at $T=0.13$ such that the mean $z_{j} / p_{j}^{\tau}$ for the lowest-skill group is 0.96 . We use the same $T$ and the same $L^{u}$ for all groups. 
in the standard Mortensen-Pissarides model in which wages are set according to Nash bargaining. Section VII.B shows that the same implications hold in the alternating-offer wage-bargaining model. Section VII.C extends the analysis to an environment with directed search and wage posting. Section VII.D shows the relevance of $z$ in an indivisible labor model.

\section{A. Canonical Search and Matching Model}

We begin by showing the importance of a cyclical $z$ within the context of the labor market search and matching framework of Mortensen and Pissarides (1994) and Pissarides (2000). We present details underlying the derivations of this section in appendix A.2. The behavior of the household is given by the model described in Section II.A. A representative firm operates the production function $Y_{t}=F_{t}\left(K_{t}, e_{t} N_{t}\right)$. The marginal value of employment for the firm, $J_{t}^{f}$, is

$$
J_{t}^{f}=p_{t}-w_{t} N_{t}+\left(1-s_{t}\right) \mathbb{E}_{t} \tilde{\beta}_{t+1} J_{t+1}^{f},
$$

where $\tilde{\beta}_{t+1}$ denotes the stochastic discount factor of the household.

The labor market is subject to search and matching frictions. The firm posts vacancies $v_{t}$ to increase employment in the next period. Each vacancy costs $\kappa$ units of the numeraire good. Trade in the labor market is facilitated by a constant returns to scale matching technology that converts searching by the unemployed and vacancies by the firm into new matches, $m_{t}=m_{t}\left(v_{t}, u_{t}\right)$. Market tightness is $\theta_{t}=v_{t} / u_{t}$. An unemployed matches with a firm with probability $f_{t}\left(\theta_{t}\right)=m_{t} / u_{t}$ and the firm fills a vacancy with probability $q_{t}\left(\theta_{t}\right)=m_{t} / v_{t}=f_{t}\left(\theta_{t}\right) / \theta_{t}$. We denote by $\eta$ the (constant) elasticity of the matching function with respect to vacancies.

The firm and the household split the surplus from an additional match according to the generalized Nash bargaining solution. The household's value of an additional match is given by equation (10) and the firm's value of an additional match is given by equation (38). The firm and the household bargain over the wage per hour worked $w_{t}$ and hours per worker $N_{t}$. Denoting by $\mu$ the bargaining power of workers, we obtain a standard wage equation augmented to take into account taxes:

$$
w_{t} N_{t}=\mu p_{t}+(1-\mu)\left(\frac{1+\tau_{t}^{C}}{1-\tau_{t}^{w}}\right) z_{t}+\mu \kappa \theta_{t} .
$$

The Nash-bargained compensation depends on the marginal product of employment, the tax-adjusted opportunity cost of employment, and a term related to labor market tightness. With Nash bargaining, hours per worker are chosen to maximize the joint surplus according to equation (29). 
We begin our analysis by following much of the literature in treating steady-state movements in the marginal product of employment $p$ and the opportunity cost of employment $z$ as exogenous. Appendix A.2 derives an expression for the elasticity of labor market tightness $\theta$ with respect to changes in the marginal product $p$ :

$$
\epsilon(\theta, p)=B\left[\frac{\left(\frac{1-\tau^{w}}{1+\tau^{C}}\right) p-z \epsilon(z, p)}{\left(\frac{1-\tau^{w}}{1+\tau^{C}}\right) p-z}\right]
$$

where $B$ is a constant and $\epsilon(z, p)$ denotes the elasticity of $z$ with respect to $p$. The response of unemployment is then given by $\epsilon(u, p)=-\eta(1-$ $u) \epsilon(\theta, p)$. Equation (40) generalizes the expressions given in Shimer (2005), Mortensen and Nagypal (2007), and Hagedorn and Manovskii (2008) to allow $z$ to change in response to changes in $p$.

Table 7 presents the elasticity of unemployment with respect to the marginal product of employment $\epsilon(u, p)$ as a function of the level $z$ and the cyclicality of the opportunity cost $\epsilon(z, p)$. Each column corresponds to the levels of $z$ that we estimated in Section V.A for different utility functions. ${ }^{40}$ As a benchmark against which to evaluate the model, we estimate that the elasticity $\epsilon\left(u_{t+1}, p_{t}\right)$ is roughly -9.5 in the data. In the first row of the table, $z$ is fixed as we vary $p$. The response of unemployment to changes in the marginal product is small when the calibrated value of $z$ is small, consistent with the result in Shimer (2005). The response of unemployment rises across columns, as the level of $z$ increases. As pointed out by Hagedorn and Manovskii (2008), a higher $z$ reduces a firm's steady-state profits. An increase in the productivity of a match then causes a larger percentage increase in profits, which strongly incentivizes the firm to create vacancies. Therefore, unemployment is more volatile.

The consequences of a cyclical $z$ can be seen by moving down the rows of table 7. A positive value of $\epsilon(z, p)$ means that $z$ increases in response to increases in $p$. The higher the responsiveness of $z$, the smaller the increase in the net flow surplus of the match, $p^{\tau}-z$, and the weaker the firm's incentive to create vacancies. As a result, holding constant the

\footnotetext{
${ }^{40}$ The other parameters for this exercise are calibrated as follows. Over our sample we estimate an average separation rate of $s=0.045$ and an average job-finding probability of $f=0.704$. Following Mortensen and Nagypal (2007), we set the elasticity in the matching function to $\eta=0.40$. We set the worker's bargaining power to $\mu=0.60$ and the discount factor to $\beta=0.99$. Finally, we use the sample averages of $\tau^{w}=0.209, \tau^{C}=0.096$, and $p=$ 1.386 , such that the after-tax marginal product equals $p^{\tau}=p\left(1-\tau^{w}\right) /\left(1+\tau^{C}\right)=1$. Under these parameters we obtain $B=1.05$.
} 
TABLE 7

Steady-State Elasticity of Unemployment with Respect to the Marginal Product

\begin{tabular}{lrrr}
\hline \hline & $z=.47$ & $z=.75$ & $z=.96$ \\
\hline$\epsilon(z, p)=.00$ & -.74 & -1.60 & -8.76 \\
$\epsilon(z, p)=.50$ & -.57 & -1.00 & -4.58 \\
$\epsilon(z, p)=.80$ & -.46 & -.64 & -2.07 \\
$\epsilon(z, p)=1.00$ & -.39 & -.39 & -.39 \\
\hline
\end{tabular}

Note.-Entries in the table denote elasticities of unemployment with respect to the marginal product.

level of $z$, the response of unemployment becomes smaller when $\epsilon(z, p)$ is higher.

Equation (40) shows analytically that if $\epsilon(z, p)=1$, so that both $z$ and $p$ change by the same percentage, the elasticities of $\theta$ and $u$ with respect to $p$ are independent of the level of $z \cdot{ }^{41}$ Table 7 shows that when $\epsilon(z, p)=$ 0.8 , the elasticity of unemployment with respect to the marginal product is 63 percent of the elasticity obtained under a constant $z=0.47,40$ percent of the elasticity obtained under a constant $z=0.71$, and 24 percent of the elasticity obtained under a constant $z=0.96$. We note that the role of cyclical movements in $z$ for unemployment fluctuations is quite general and does not rest on productivity shocks driving fluctuations in the model. The crucial determinant of unemployment volatility is the responsiveness of $z$ relative to the responsiveness of $p$ when some shock hits the economy, with the relative responsiveness given by $\epsilon(z, p)$.

We reach a similar conclusion when we conduct business cycle analysis in the Mortensen-Pissarides/RBC model. In appendix A.2 we present results from simulations of the Mortensen-Pissarides/RBC model driven by exogenous TFP shocks. We show that, under a high level of $z=0.96$ that is restricted to be constant over time because there is no disutility from working, the model generates volatile unemployment fluctuations (with an elasticity $\epsilon\left(u_{t+1}, p_{t}\right)$ of around -6.5$)$. This result is consistent with the analysis of Hagedorn and Manovskii (2008), who find volatile unemployment fluctuations in a model in which $z$ is high but constant. When there is disutility from working, $z$ varies endogenously over time (see Sec. II.B.3). We show that with disutility from working, the model generates cyclical movements in $z$ similar to those documented in the data, with the elastic-

${ }^{41}$ In a model with labor market frictions, concave utility over consumption, and a positive value of time, Blanchard and Gali (2010) show that unemployment is neutral with respect to fluctuations in productivity. In their model consumption moves one to one with productivity because of the lack of capital. Because they do not consider benefits and fluctuations in hours per worker, their $z$ also moves one to one with productivity. In our case unemployment fluctuations are small but not zero when $\epsilon(z, p)=1$. The difference is explained by the fact that in eq. (40) we have assumed that vacancy costs $\kappa$ are constant. Blanchard and Gali instead assume that hiring costs scale one to one with productivity. 
ity $\epsilon\left(z_{t}, p_{t}\right)$ being around 0.8 . The model with time-varying $z$ generates a significantly lower unemployment volatility, with the elasticity $\epsilon\left(u_{t+1}, p_{t}\right)$ ranging from -1.7 to -0.3 . These results hold for various levels of $z$ that range from 0.47 to 0.96 .

\section{B. Alternating-Offers Bargaining Model}

Hall and Milgrom (2008) replace Nash bargaining with an alternative wage-setting mechanism. In their alternating-offer bargaining game, when a firm with a vacancy meets an unemployed, the firm offers a compensation package $\tilde{w}$. The unemployed can accept the offer and commence work or prolong the bargaining and make a counteroffer $\tilde{w}^{\prime}$. Crucially, $z$ parameterizes the flow opportunity cost of prolonging the bargaining and hence the threat point if the unemployed deems the employer's initial offer too low. ${ }^{42}$ With a constant $z$, wages therefore respond weakly to increases in $p$. The rigidity of wages incentivizes firms to significantly increase their job creation. ${ }^{43}$ Allowing instead $z$ to comove with $p$ in the alternating-offer bargaining model makes the unemployed's threat point again sensitive to aggregate conditions. This increases the flexibility of wages and reduces the volatility of unemployment.

We illustrate this point using the linear search and matching model presented in Hall and Milgrom (2008). We first replicate their results for three linear models, the Nash bargaining model with $z=0.71$ (standard Mortensen-Pissarides), the Nash bargaining model with $z=0.93$ (Hagedorn-Manovskii), and the alternating-offer bargaining model with $z=0.71$ (Hall-Milgrom). Then we introduce in these models a cyclical $z$ with $\epsilon(z, p)=1$. Appendix A.3 presents the equations and parameters of Hall and Milgrom, which we adopt here.

Table 8 summarizes our results. We begin with the cases of a constant $z$. The first row shows the slope of the expected present value of utility flows for the unemployed $\tilde{U}^{u}$ with respect to the expected present value of a newly hired worker's product $\tilde{p}$. With Nash bargaining, $\tilde{U}^{u}$ is the outside option of the unemployed while bargaining. It helps to separate $\tilde{U}^{u}$ into the sum of two components: the expected present value from receiving $z$ discounted by the probability the individual remains unemployed and the value of obtaining a job in a future period discounted by the probability of exiting unemployment in that period. In the standard

${ }^{42}$ Another important parameter is the probability (denoted by $\delta$ in Hall and Milgrom [2008]) that the bargaining exogenously falls apart and the unemployed returns to the general search pool. This probability governs the extent to which the wage depends on $z$ rather than on wage offers at other firms.

${ }^{43}$ Christiano, Eichenbaum, and Trabandt (2013) embed the Hall and Milgrom (2008) model of wage bargaining into a New Keynesian dynamic general equilibrium model and show that the estimated model outperforms the standard Mortensen-Pissarides model in several dimensions including volatility in the labor market. 
TABLE 8

Cyclicality of Wages and Unemployment Fluctuations

\begin{tabular}{|c|c|c|c|c|c|c|}
\hline \multirow[b]{2}{*}{ Statistic } & $\begin{array}{r}\text { Stan } \\
\text { Mort } \\
\text { PISSA }\end{array}$ & $\begin{array}{l}\text { ARD } \\
\text { NSEN- } \\
\text { RIDES }\end{array}$ & \multicolumn{2}{|c|}{$\begin{array}{l}\text { HAGEDORN- } \\
\text { MANOVSKII }\end{array}$} & \multicolumn{2}{|c|}{ Hall-Milgrom } \\
\hline & Constant $z$ & Cyclical z & Constant $z$ & Cyclical z & Constant $z$ & Cyclical z \\
\hline Slope $\mathrm{d} \tilde{U}^{u} / \mathrm{d} \tilde{p}$ & 1.14 & 1.30 & .87 & 1.32 & 1.19 & 1.31 \\
\hline Slope $\mathrm{d} \tilde{w} / \mathrm{d} \tilde{p}$ & .93 & .98 & .71 & .98 & .69 & .91 \\
\hline Elasticity $\epsilon(u, p)$ & -1.51 & -.44 & -5.87 & -.40 & -6.02 & -1.75 \\
\hline
\end{tabular}

Note.-The table reports model statistics. Standard Mortensen-Pissarides corresponds to a model with Nash bargaining over wages and a mean level of $z$ of 0.71 ; Hagedorn-Manovskii corresponds to a model with Nash bargaining over wages and a mean level of $z$ of 0.93 ; and Hall-Milgrom corresponds to a model with alternating-offer bargaining over wages.

Mortensen-Pissarides model with Nash bargaining and a constant $z, \tilde{U}^{u}$ responds substantially when $\tilde{p}$ increases (with $\mathrm{d} \tilde{U}^{u} / \mathrm{d} \tilde{p}=1.14$ ). Intuitively, a low $z$ means that future job prospects contribute relatively more to $\tilde{U}^{u}$, and a higher $\tilde{p}$ increases the probability of an unemployed finding a high-wage job. In the Hagedorn-Manovskii model with Nash bargaining and a high $z$, the expected present value of $z$ is a more important component of $\tilde{U}^{u}$. Because $z$ is constant, $\tilde{U}^{u}$ responds less to the better job prospects created by a higher $\tilde{p}$ (with a $\mathrm{d} \tilde{U}^{u} / \mathrm{d} \tilde{p}=0.87$ ).

The second row shows the slope of the expected present value of wage payments $\tilde{w}$ with respect to $\tilde{p}$. In the standard Mortensen-Pissarides model, the significant increase in the unemployed's outside option makes wages respond flexibly to productivity changes (with $\mathrm{d} \tilde{w} / \mathrm{d} \tilde{p}=0.93$ ). In the Hagedorn-Manovskii model, the smaller increase in the outside option makes the wage more rigid (with $\mathrm{d} \tilde{w} / \mathrm{d} \tilde{p}=0.71$ ). As shown in the third row of table 8 , the lower response of wages to productivity changes in the Hagedorn-Manovskii calibration is associated with significantly larger responses of unemployment than the ones obtained in the standard Mortensen-Pissarides model.

Turning to the Hall and Milgrom model with constant $z$, here too the change in job prospects of an unemployed makes $\tilde{U}^{u}$ sensitive to variations in $\widetilde{p}$. However, with alternating-offer bargaining, returning to the general search pool with value $\tilde{U}^{u}$ no longer constitutes the unemployed's outside option. Instead, the unemployed's threat point is to continue to bargain, in which case he receives a flow value $z$. Because $z$ is constant, wages do not respond significantly to productivity changes (with $\mathrm{d} \tilde{w} / \mathrm{d} \tilde{p}=0.69$ ) and unemployment responds significantly.

To summarize, both the Hagedorn and Manovskii (2008) calibration and the Hall and Milgrom (2008) alternating-offers model achieve significant unemployment responses in part by generating endogenous wage rigidity. In both cases, the wage rigidity comes from increasing the importance of $z$ to the unemployed's outside option, in Hagedorn and 
Manovskii (2008) by calibrating a higher $z$, and in Hall and Milgrom (2008) by changing the bargaining game to increase the weight of $z$ in the outside option. This logic makes clear why both models no longer generate volatile unemployment if $z$ moves cyclically. In that event, the outside option in both models again becomes sensitive to productivity, wages become responsive, and the firm's incentive to increase employment following a positive shock to $\tilde{p}$ becomes weaker. The columns labeled cyclical $z$ in table 8 illustrate this point quantitatively. ${ }^{4}$

\section{Directed Search and Wage Posting Model}

The role of $z$ in the random search and matching framework extends into the environment pioneered in Shimer (1996) and Moen (1997) with directed search and wage posting. Here we summarize the argument and defer to appendix A.4 a more detailed presentation of the model as well as the derivations underlying our analysis.

We augment the basic environment described in Section II to have $M$ distinct employment submarkets indexed by $i=1,2, \ldots, M$. All submarkets have the same matching technology, production technology, and job separation rate. In each submarket, a triplet $\{w(i), N(i), \theta(i)\}$ describes the posted wage, posted hours per worker, and the vacancyunemployment ratio.

The household maximizes the objective function (2), augmented to allow hours and consumption of employed to vary across submarkets. Similarly, the budget constraint of the household is given by equation (3) but with labor income $w_{t} N_{t} e_{t}$ replaced by the sum of income earned in $M$ submarkets $\Sigma_{i} w_{t}(i) N_{t}(i) e_{t}(i)$. There are $M$ laws of motion for employment, $e_{t+1}(i)=\left(1-s_{t}\right) e_{t}(i)+f_{t}(i) u_{t}(i)$. The household chooses the allocation of consumption across its members and, additionally, how to optimally allocate searchers across submarkets. The marginal value to the household of an additional employed in submarket $i$ is

$$
\begin{aligned}
\frac{J_{t}^{h}(i)}{\lambda_{t}}= & \left(\frac{1-\tau_{t}^{w}}{1+\tau_{t}^{C}}\right) w_{t}(i) N_{t}(i)-z_{t}(i) \\
& +\mathbb{E}_{t} \frac{\beta \lambda_{t+1}}{\lambda_{t}}\left[1-s_{t}-f_{t}(i)\right] \frac{J_{t+1}^{h}(i)}{\lambda_{t+1}} .
\end{aligned}
$$

In the appendix we solve for a symmetric equilibrium in which all firms post the same wage and hours and $\theta_{t}(i)=\theta_{t}$ is the same in all sub-

${ }^{44}$ With cyclicality in $z$, the Hall-Milgrom model performs better than the HagedornManovskii model. The reason is that in the Hall-Milgrom model, wages partly depend on a firm-specific cost of continuing bargaining (denoted by $\gamma$ ), which is assumed to be constant over time. Making $\gamma$ comove with the aggregate state ameliorates even more the unemployment fluctuations generated by the model. 
markets. With symmetric hours, consumption bundles also do not differ across submarkets. As a result, we obtain $z_{t}(i)=z_{t}$ in equation (41), where $z_{t}$ is again defined as in equation (10). Therefore, the same measure of opportunity cost also appears in the model with directed search and wage posting.

The steady-state elasticity of overall market tightness $\theta$ with respect to shocks to the marginal product $p$ is given by

$$
\epsilon(\theta, p)=\bar{B}\left[\frac{\left(\frac{1-\tau^{w}}{1+\tau^{C}}\right) p-z \epsilon(z, p)}{\left(\frac{1-\tau^{w}}{1+\tau^{C}}\right) p-z}\right],
$$

where $\bar{B}$ is a constant. The elasticities $\epsilon(\theta, p)$ defined in equation (42) for the directed search model and in equation (40) for the Nash bargaining model are identical up to the constants $\bar{B}$ and $B$. As a result, the implications of a cyclical $z$ in the Nash bargaining environment also apply to an environment with directed search. The constants $\bar{B}$ and $B$ in the two models coincide exactly when the bargaining power of workers $\mu$ equals the absolute value of the elasticity of the job-filling rate $q$ with respect to market tightness $\theta$.

\section{Indivisible Labor Model}

In the models considered so far employment is a state variable. We now discuss the indivisible labor model of Hansen (1985) and Rogerson (1988). The household maximizes the objective function in equation (2) subject to the budget constraint in equation (3). The key difference relative to the search and matching model is that, instead of facing the exogenous law of motion for employment in equation (1), the household now chooses freely the number of employed $e_{t}$ in each period. ${ }^{45}$

The marginal value of employment in this model is simply

$$
\frac{J_{t}^{h}}{\lambda_{t}}=\left(\frac{1-\tau_{t}^{w}}{1+\tau_{t}^{C}}\right) w_{t} N_{t}-z_{t},
$$

where $z_{t}$ is still defined as in equation (10). Thus, the same measure of the opportunity cost also arises in the indivisible labor model. Equation

${ }^{45}$ As in Hansen (1985) and Rogerson (1988), this problem can be microfounded in a model in which many ex ante similar individuals choose the probability $e_{t}$ of employment. A lottery then determines which individuals actually work. Individuals have access to an insurance market that provides consumption equal to $C_{t}^{e}$ when employed and $C_{t}^{u}$ when unemployed. Only if preferences are separable in hours $N_{t}$, then $C_{t}^{e}=C_{t}^{u}$. 
(43) implies a step function for the supply of labor along the extensive margin. If the after-tax labor income is below the opportunity cost (i.e., $\left.J_{t}^{h}<0\right)$, then $e_{t}=0$. If the after-tax labor income exceeds the opportunity cost (i.e., $J_{t}^{h}>0$ ), then $e_{t}=1$. If the after-tax labor income equals the opportunity cost $\left(J_{t}^{h}=0\right)$, then the household supplies any employment $e_{t} \in[0,1]$. To close the model, one can assume a downward-sloping labor demand function relating $w_{t} N_{t}$ to $e_{t}$. In an interior equilibrium, $w_{t} N_{t}(1-$ $\left.\tau_{t}^{w}\right) /\left(1+\tau_{t}^{C}\right)=z_{t}$.

The consequences of a procyclical $z$ for employment fluctuations apply equally well to the indivisible labor model. To see this, suppose that $z$ is constant (for instance, because $b$ is constant and there is no disutility from labor). A given decrease in labor demand with constant $z$ causes a large drop in equilibrium employment $e$ without any change in the equilibrium wage $w$. Next, in response to the same decrease in labor demand, suppose that $z$ also falls. The drop in the equilibrium $e$ is now smaller and the equilibrium $w$ also declines.

\section{Conclusion}

The flow value of the opportunity cost of employment falls during recessions. The key mechanism is that the household values most the contribution of the employed (through higher wage income) relative to that of the unemployed (through higher nonworking time) when market consumption is low and nonworking time is high. This more than offsets the effect of the increase in government benefits.

A procyclical opportunity cost reduces unemployment volatility in models in which $z$ affects the wage bargain. Our preferred estimate of the elasticity of the opportunity cost with respect to the marginal product of employment is close to unity. With this value and Nash bargaining, fluctuations in unemployment generated by the model are essentially neutral with respect to the level of $z$ and remain far smaller than unemployment fluctuations in the data. We reach a similar outcome in a model in which wages are determined by alternating offers or when the labor market has directed search and wage posting.

An interpretation of our results is that endogenous forms of wage rigidity, such as accomplished by Hagedorn and Manovskii (2008) and by Hall and Milgrom (2008), do not survive the introduction of a cyclical flow opportunity cost. Without rigid wages, these models cannot generate volatile unemployment. This pessimistic conclusion does not apply to models in which wages are exogenously sticky or are selected according to some process that does not depend on the opportunity cost of employment. Alternatively, using the Brugemann and Moscarini (2010) decomposition of wages into payments covering opportunity costs and rents due to frictions, the procyclicality of $z$ implies that wage rigidity re- 
quires substantial countercyclicality in rents. The extent to which actual wages vary cyclically remains an open and important question (see Hall and Milgrom [2008] and Pissarides [2009] for contrasting views).

Our results also bear on recent work emphasizing the role of social safety net expansions in propagating the increase in unemployment during the Great Recession (Hagedorn et al. 2013). We find, contrary to this hypothesis, that fluctuations in the value of benefits have only a small effect on the opportunity cost of employment. However, we have not modeled the complicated set of benefit phase-out schedules, considered in Mulligan (2012), that can give rise to high implicit marginal tax rates along the intensive margin or affect the decision to move out of the labor force.

\section{References}

Aguiar, Mark, and Erik Hurst. 2005. “Consumption versus Expenditure.” L.P.E. 113 (5): 919-48.

Aguiar, Mark, Erik Hurst, and Loukas Karabarbounis. 2013. "Time Use during the Great Recession.” A.E.R. 103 (5): 1964-96.

Anderson, Patricia, and Bruce Meyer. 1997. "Unemployment Insurance Takeup Rates and the After-Tax Value of Benefits." O.J.E. 112 (3): 913-37.

Bils, Mark, Yongsung Chang, and Sun-Bin Kim. 2012. "Comparative Advantage and Unemployment." L. Monetarv Econ. 59:150-65.

Blanchard, Olivier, and Jordi Gali. 2010. "Labor Markets and Monetary Policy: A New Keynesian Model with Unemployment." American Econ. I.: Macroeconomics 2 (2): $1-30$.

Blank, Rebecca, and David Card. 1991. "Recent Trends in Insured and Uninsured Unemployment: Is There an Explanation?” O.J.E. 106 (4): 1157-89.

Blundell, Richard, Luigi Pistaferri, and Ian Preston. 2008. "Consumption Inequality and Partial Insurance.” A.E.R. 98 (5): 1887-1921.

Browning, Martin, and Thomas Crossley. 2001. "Unemployment Insurance Benefit Levels and Consumption Changes." L. Public Econ. 80 (1): 1-23.

Brugemann, Bjorn, and Giuseppe Moscarini. 2010. "Rent Rigidity, Asymmetric Information, and Volatility Bounds in Labor Markets." Rev. Econ. Dynamics 13 (3): 575-96.

Burgess, Paul, Jerry Kingston, Robert St. Louis, and Joseph Sloane. 1981. "Changes in Spending Patterns Following Unemployment." Occasional Paper no. 81-3, Employment and Training Admin., US Dept. Labor, Washington, DC.

Christiano, Lawrence, Martin Eichenbaum, and Mathias Trabandt. 2013. "Unemployment and Business Cycles.” Working Paper no. 19265, NBER, Cambridge, MA.

Cociuba, Simona, Edward Prescott, and Alexander Ueberfeldt. 2012. "U.S. Hours and Productivity Behavior Using CPS Hours." Working paper, Arizona State Univ.

Costain, James, and Michael Reiter. 2008. "Business Cycles, Unemployment Insurance, and the Calibration of Matching Models." L.Econ. Dvnamics and Control 32:1120-55.

Feldstein, Martin, and James Poterba. 1984. "Unemployment Insurance and Reservation Wages." L. Public Econ. 23 (1-2): 141-67.

Fernald, John. 2012. "A Quarterly, Utilization-Adjusted Series on Total Factor Productivity.” Working Paper no. 2012-19, Fed. Reserve Bank San Francisco. 
Gruber, Jonathan. 1997. "The Consumption Smoothing Benefits of Unemployment Insurance." A.E.R. 87 (1): 192-205.

Hagedorn, Marcus, Fatih Karahan, Iourii Manovskii, and Kurt Mitman. 2013. "Unemployment Benefits and Unemployment in the Great Recession: The Role of Macro Effects." Working Paper no. 19499, NBER, Cambridge, MA.

Hagedorn, Marcus, and Iourii Manovskii. 2008. "The Cyclical Behavior of Equilibrium Unemployment and Vacancies Revisited." A.E.R. 98 (4): 1692-1706.

Hall, Robert. 2005. "Employment Fluctuations with Equilibrium Wage Stickiness." A.E.R. 95 (1): 50-65.

2009. "Reconciling Cyclical Movements in the Marginal Value of Time and the Marginal Product of Labor." L.P.E. 117 (2): 281-323.

. 2014. "High Discounts and High Unemployment." Working paper, Stanford Univ.

Hall, Robert, and Paul Milgrom. 2008. "The Limited Influence of Unemployment on the Wage Bargain." A.E.R. 98 (4): 1653-74.

Hall, Robert, and Andreas Mueller. 2013. "Wage Dispersion and Search Behavior." Working paper, Stanford Univ.

Hansen, Gary D. 1985. "Indivisible Labor and the Business Cycle." L. Monetary Econ. 16 (3): 309-27.

Hornstein, Andreas, Per Krusell, and Giovanni Violante. 2005. "Unemployment and Vacancy Fluctuations in the Matching Model: Inspecting the Mechanism." Fed. Reserve Bank Richmond Econ. Q. 91 (3): 19-51.

Krueger, Alan, and Andreas Mueller. 2013. "A Contribution to the Empirics of Reservation Wages.” Working paper, Columbia Univ.

Mendoza, Enrique, Assaf Razin, and Linda Tesar. 1994. "Effective Tax Rates in Macroeconomics: Cross-Country Estimates of Tax Rates on Factor Incomes and Consumption." L. Monetarv Econ. 34:297-323.

Meyer, Bruce, Wallace Mok, and James Sullivan. 2009. "The Under-reporting of Transfers in Household Surveys: Its Nature and Consequences." Working Paper no. 15181, NBER, Cambridge, MA.

Moen, Espen R. 1997. “Competitive Search Equilibrium.” L.P.E. 105 (2): 385-411.

Mortensen, Dale T., and Eva Nagypal. 2007. "More on Unemployment and Vacancy Fluctuations." Rev. Econ. Dvnamics 10 (3): 327-47.

Mortensen, Dale T., and Christopher A. Pissarides. 1994. "Job Creation and Job Destruction in the Theory of Unemployment." Rev. Econ. Studies 61 (3): 397-415.

- 1999. "Unemployment Responses to 'Skill-Biased' Technology Shocks: The Role of Labour Market Policy." Econ. I. 109 (455): 242-65.

_. 2001. "Taxes, Subsidies and Equilibrium Labor Market Outcomes." Discussion Paper no. 519, Centre Econ. Performance, London School Econ.

Mulligan, Casey. 2012. The Redistribution Recession. Oxford: Oxford Univ. Press.

Pissarides, Christopher A. 1985. "Short-Run Equilibrium Dynamics of Unemployment, Vacancies, and Real Wages." A.E.R. 75 (4): 676-90.

. 2000. Equilibrium Unemployment Theory. Cambridge, MA: MIT Press.

. 2009. "The Unemployment Volatility Puzzle: Is Wage Stickiness the Answer?" Econometrica 77 (5): 1339-69.

Pistaferri, Luigi. 2003. "Anticipated and Unanticipated Wage Changes, Wage Risk, and Intertemporal Labor Supply.” L. Labor Econ. 21 (3): 729-54.

Rogerson, Richard. 1988. "Indivisible Labor, Lotteries, and Equilibrium." L. Monetary Econ. 21 (1): 3-16.

Rogerson, Richard, and Johanna Wallenius. 2013. "Nonconvexities, Retirement, and the Elasticity of Labor Supply." A.E.R. 103 (4): 1445-62. 
Rogerson, Richard, and Randall Wright. 1988. "Involuntary Unemployment in Economies with Efficient Risk Sharing." L. Monetary Econ. 22:501-15.

Saporta-Eksten, Itay. 2014. "Job Loss, Consumption, and Unemployment Insurance." Working paper, Stanford Univ.

Shimer, Robert. 1996. "Contracts in Frictional Labor Markets." Working paper, Massachusetts Inst. Tech.

. 2005. "The Cyclical Behavior of Equilibrium Unemployment and Vacancies." A.E.R. 95 (1): 25-49. Press.

. 2010. Labor Markets and Business Cycles. Princeton, NJ: Princeton Univ.

2012. "Reassessing the Ins and Outs of Unemployment." Rev. Econ. Dynamics 15:127-48.

Stephens, Melvin. 2004. "Job Loss Expectations, Realizations, and Household Consumption Behavior." Rev. Econ. and Statis. 86 (1): 253-69.

Trabandt, Mathias, and Harald Uhlig. 2011. "The Laffer Curve Revisited." L. Monetary Econ. 58 (4): 305-27. 